\title{
Additive Manufacturing of Fatigue Resistant Materials: Challenges and Opportunities
}

\author{
Aref Yadollahi and Nima Shamsaei, ${ }^{\mathrm{b}, *}$ \\ ${ }^{a}$ Department of Mechanical Engineering, Mississippi State University, MS 39762, USA \\ ${ }^{b}$ Department of Mechanical Engineering, Auburn University, Auburn, AL36849, USA \\ *Corresponding author: \\ Email:shamsaei@auburn.edu
}

Phone: (334) 8444839

Submitted to:

International Journal of Fatigue

Original submission: October 2016

Revised submission: December 2016

(C) 2017. This manuscript version is made available under the Elsevier user license http://www.elsevier.com/open-access/userlicense/1.0/ 


\begin{abstract}
This overview article focuses on the current state of knowledge pertaining to the mechanical characteristics of metallic parts fabricated via additive manufacturing (AM), as well as the ongoing challenges and imminent opportunities in fabricating more fatigue resistant materials. Current experimental evidence suggests that the mechanical properties of laboratory AM specimens may not be representative ofthose associated with parts, due primarily to differences in geometry/size which influence the thermal histories experienced during fabrication, and consequently, microstructural features, surface roughness and more. In addition, standards for mechanical testing methods, specimen design procedures, post-manufacturing treatments, etc., may need to be revisedfor AM parts. Standardizing the AM processmay only be accomplished by strengthening the current understanding of the interrelationships among process parameters, thermal history, solidification, resultant microstructure, and mechanicalbehavior ofthe part.Having the ability to predict variation in mechanical behavior based on resultant microstructure, or matching the best conceivable properties of a part in accordance with the loading critical plane,are some possible solutionsfor making AM a more reliable means for producing functional parts. Developingmicrostructure-property modelsis arguably the first, necessary step towarddesign optimization and the more efficient, accurate estimation of the structural integrity ofAM parts.
\end{abstract}

\title{
Keywords:
}

Additive Manufacturing (AM); Fatigue; Microstructure-Property; Multiaxial Loading; Review 


\section{Nomenclature}

$\begin{array}{ll}k & \text { Material constant } \\ N_{\mathrm{f}} & \text { Number of cycles to failure } \\ 2 N_{\mathrm{f}} & \text { Number of reversals to failure } \\ \mathrm{R}_{\mathrm{a}} & \text { Surface roughness } \\ R_{\varepsilon} & \text { Strain ratio } \\ R_{\sigma} & \text { Stress ratio } \\ \Delta \gamma_{\max } / 2 & \text { maximum shear strain amplitude } \\ \Delta \varepsilon / 2, \varepsilon_{\mathrm{a}} & \text { Strain amplitude } \\ \Delta \sigma / 2, \sigma_{\mathrm{a}} & \text { Stress amplitude } \\ \varepsilon & \text { Axial strain } \\ \sigma & \text { Axial stress } \\ \sigma_{\mathrm{n}, \max } & \text { Normal stress acting on the plane of maximum shear strain } \\ \sigma_{\mathrm{y}} & \text { Monotonic yield stress }\end{array}$

\section{Glossary}

3D Three-dimensional

AM Additive manufacturing

CT Computed tomography

DLD Direct laser deposition

FS Fatemi-Socie

HCF High cycle fatigue

HIP Hot isostatic pressing

IP In-phase

ISV Internal state variable

LCF Low cycle fatigue

LENS Laser engineered net shaping

L-PBF Laserpowder bed fusion

MSF Multi-stage fatigue

OP Out-of-phase

PBF Powder bed fusion

$\mathrm{PH} \quad$ Precipitation hardening

SLM Selective laser melting

SS Stainless steel 


\section{Introduction}

According to the American Society for Testing andMaterials (ASTM),additive manufacturing (AM) is defined as the "process of joining materials to make objects from three-dimensional (3D) model data, usually layer upon layer, as opposed to subtractive manufacturing methodologies” [1].AM is a common term used to describe a group of advancedmanufacturing technologies that create objects in a layer-wise method. There are different types of AM techniques depending on the feed stock form (e.g., powder versus wire),feeding system (e.g., powder bed versus blown powder), energy source (e.g., laser versus electron beam), materials (e.g., metal versus polymer), etc.[2-4].This overview is based on those that use the focused laser beam as a source of energy to melt metallic powder for forming a part.These types of AM methods can be classified in two main categories: (i) laser powder bed system (L-PBF) in which a bed of powder serves as the feeding system, such as selective laser melting (SLM); and (ii) direct laser deposition (DLD) which employs a blown powder system, such as laser engineered net shaping (LENS)[2].

These new manufacturing techniques have provided new avenues for fabricatingnetshapedparts, or even assemblies, with complex geometries in ways that traditional manufacturing methodologiesare unable.New developments in AM processes, along with innovations in advanced materials, haveenabledmore unique approachesfor product development, manufacturing, and supply chain management[5,6]. Since AM has less geometrical constraints, industries will benefit from AM by finding new design paradigms for achievinglighter and cleanerproducts, as well as shorter lead times with lower costs.Moreover, AM can streamline the manufacturing and assembly process sinceassemblies can be consolidated into a single additive part, leading to reduced number of parts and cost savings [2-4,7]. 
Additive manufacturing perhaps has the most appeal to industries targeting lowvolume production ofhighly customized parts for specific applications, especially in the medical arena[8]. Surgical instruments and patient/injury-specific implants can be generated via AM for reducing patient wait times and accelerating their post-implant healing process.Via AM, more individualized medical equipment/tools can be generatedand delivered more rapidly, with reasonable pricing $[5,6]$.Beside these, AM providesthe ability of remote manufacturing and repair (in space, on ship)on demand as well as manufacturing of functionally-graded parts.Hence, AM has gained considerable attentionfromvarious industries such as aerospace and biomedical to fabricate functional service parts.However, the potential for AM to provide for a new means to manufacture load bearing (i.e. structural)parts is not yet fully realized[9].

The main challengeagainst the continual adoption of AMby industries is theuncertainty in structural properties of their fabricated parts[3,4,9].This uncertaintyarises due to AM parts possessingmicrostructural heterogeneities and randomly dispersed defects[9]. In addition tovariation in as-received powder characteristics, building procedure, and AM systems, this challenge is exacerbatedby the many involved process parameters, such as: laser power, laser speed, layer thickness, etc., which affect thermal history during fabrication[3,4,9]. Thermal history (i.e. melt pool temperature, thermal gradient, cooling rate, cyclic reheating)in AM process affects the microstructural details,such as: grain size, morphology, and texture; defect type, size, and spatial distribution; residual stress, etc., and consequently, mechanical behavior of fabricated part[9].

Although significant research effort has been devoted to parameter optimization/control to achieve more uniform microstructure in $\mathrm{AM}$ parts[2,10], undesirable consequences of this manufacturing method on material properties are inevitableand overcoming this challenge is still 
an open issue [9]. In addition, even under fixed, optimized process parameters, any change in build parameters, such as part size and build orientation may cause variation inmicrostructural, and consequently, mechanical characteristics [11,12]. As a result, there are still significant gaps tofully understand and establishthe relationship between theprocess, structure, property, and performance of AMparts[13].

In this overview, thefatigue characteristics and related challenges inherent tometallic parts fabricated via laser-based additive manufacturing arediscussed. It should be noted that, the goal of this paper is not to includeallthe existing studies related to AM, but to provide an overviewmostly based on authors' research work to emphasize the important and imminent challengespertaining to characterizing the fatigue behavior of AM metals. There are definitely other related topics to thestructural integrity of AM parts, such asresidual stresses, very high cycle fatigue behavior, and more, that are not discussed in this overview.

The organization of this paper is as follows: fatigue behaviorof AM materials and their comparison with conventionally-built counterparts are described in Section 2. Next, the effects of size, time interval and geometry on mechanical behavior and microstructural properties of AM partsare presented in Section 3. Section 4 discusses anisotropy in mechanical properties (i.e. tensile and fatigue), imposed by part's build orientation during AM process. The effect of surface finish on fatigue resistance and failure mechanism of AM parts is described in Section 5. Someopportunities in additive manufacturing of more fatigue resistant materials are discussed in Section 6. Finally, a summary of this manuscript along with some conclusions is provided in Section 7. 


\section{Fatigue behavior and failure mechanisms}

In general, the mechanical properties under static loading, including tensile,compressive, hardness, etc., of AM parts are comparableto their conventionally-fabricated forms[14]. This is primarily due to the fact that $\mathrm{AM}$ parts experience relatively highcooling rates during theirfabrication, resulting infiner microstructure as compared totheir conventionally-fabricated counterparts[4,9,15,16]. Although there exists a number of worksfocused on mechanical characterization of AM parts, their mechanical behavior, including the trustworthiness and durability,is still not well understood [9].

A major challenge and concern for metallic AM parts in application is their performance under cyclic loading, i.e. their fatigue resistance - a common modefor mechanical failure in manyengineering structures[9,11,17].Contrary to failures that occur under static loading, failure by fatigue is mostly a local phenomenon driven by impurities and microstructural heterogeneity; traits descriptive of metallic parts fabricated using currentAM technology[9,11,17]. Therefore, improvingthe trustworthiness anddurabilityof engineering parts fabricated via AM cannot be achieved withouta thorough understandingofthe fatigue damage process, failure mechanisms, and more specifically, their relationships with the microstructure of AM materials.

Due to variationin post-manufacturing processes, material feedstock, specimen types(round versus flat), testingmodes(strain-controlled versus force-controlled), etc., it is difficult to make direct comparisons between fatigue data obtained from AM materialsand those obtained from conventionally-built parts of the same material asreported in the literature. However, to facilitate general discussion, some fatigue data related to AM parts such as DLD Ti-6Al-4V (as-built without any heat treatments)[18], L-PBF 17-4 PH stainless steel (SS) (heat treated) [11], and LPBF Inconel 718 (hot isostatic pressed and heat treated)[19] arecompared with those of 
corresponding wrought materials at room temperature reported elsewhere [20-23].These data arepresented in Fig. 1.As seen in this figure, AM materials exhibit significantly shorter fatigue lives and lower high cycle fatigue (HCF)strength as compared to their corresponding wrought material form. Other studies [15,24-26] have also reported such lower fatigue resistance for AM parts; regardless of the manufacturing method and material type. It is wellestablished that the surface roughness of parts canadversely affect itsfatigue behavior[17].Hence, in order to provide a more reasonable and unbiased comparison between the AM parts, which typically possess surface roughness, with fatigue data corresponding to their wrought material forms, data pertaining to AM parts in their machined and/or polished surface conditions were selected for this comparison.

Considering the fact that the ultimate tensile strength of AM materials, investigated previously by the authors[11,18,19], wasalmost similar to that of wrought counterparts, the shorter fatigue life of AM materials - especially inhigh cycle fatigue(HCF) - can be explained by the presence of defects, whichcan serve as crack initiation sites. Figure 1presents the crack initiation sites for the previously-investigated DLD Ti-6Al-4V[18], L-PBF 17-4 PH SS[11], and L-PBF Inconel 718[19] specimens. Fractography of the failed specimens reveal that, regardless of the manufacturing method and material type, crackstend to initiate from voids induced during the powder-based AM process,as shown in Fig. 1[11,18,19].

Further microstructural examination and fractography ofAM materials has revealeddifferent types of defects,such as voids and particles,asthe main sources of damage $[11,18,19]$. Voidscanbe classified asporesor un-melted regions (i.e. weakmetallurgical bondingbetween layers, so-called lack of fusion). The existence of pores is predominantly attributed to entrapped gas; a result of vapor recoil during melt pool formation or non-ideal formation of powders during 
their fabrication. Un-melted regions within AM parts form due to insufficient fusion and/orlow laser penetration depth during fabrication.Pores are typically small in size and possess a spherical-shape, whereas un-melted regionsare irregularly-shaped, and most importantly, slitshaped.Particle inclusions may be classified as partially- or un-melted powder particles, caused by ineffective fusion, and primary/secondary phase particles, formed during solidification.

In wrought materials, slip bands and microstructural weak points (e.g., microstructural defects and grain boundaries)typically compete together for initiating cracks - byproviding local plastic deformation under cyclic loading. However, current analysis of the fatigue fracture surfacesreveal that cracks initiate from voids located closer to the surface of AM parts, which seems to be the most life limiting failure mechanism for AM materials[11,18,19,26]. Such surface voids provide therequired stress concentration to initiate a crack at a lowernumber of fatigue cycles.

Location, shape, and sizeof voids have been found to be the main contributorfor the larger scatter in HCF data of AM materials[11,18,19,26]. Since the crack initiation stage dominates the total fatigue lifetime in HCF, sensitivity to defects is more pronounced as compared to thelow cycle fatigue (LCF) regime, where the crack propagation stage typically dominates the total fatigue lifetime[17].Although the mechanisms for crack initiation depend on the material as well as applied stress/strain level (i.e. LCF versus HCF), voids with larger size, more irregular shape, and closer to the surface are found to be more detrimental to fatigue resistance due to their provision of higher stress concentrations[11].

Results have shown that for most cases, the failure mechanism for AM materials is more affected by void location as opposed to its shape or size, ascrack initiation sites are observed to be closer to the specimens’ surface[11,19,26,27]. In fact, an AM part consisting ofhigh intra-part 
void density (i.e. large voids or clusterof voids), located far from surface, still does not exceed the dominating and detrimental influence of a near-surface void with regards to crack initiation[27].Surprisingly, fatigue experiments on DLD NiTi(also known as Nitinol)[26]have demonstratedthat, regardless of the location, shape, and size of the microstructural defect, fatigue life is always shorter for the duplicate specimen with higher stress response (i.e. the average net section stress). This observation indicates that the maximum stress level may bethe most influential factor on the fatigue behavior of additively-manufactured superelastic NiTi [26,28].

Hot isostatic pressing (HIP) is often considered as the most effective post-manufacturing treatment available forremedying process related defects of AM partsand improving their fatigue performance[24,29]. Via HIP, it is possible to homogenize the microstructure of AM parts while also densifyingand stress relievingtheir matrix, as HIP uses the combined action of high pressure and temperature. Several studies have shown that employing HIP on AM Ti-6Al-4V can significantly improve its fatigue resistance, resulting in comparable fatigue strengthrelative to their wrought counterparts[24,30,31]. However,these findingscannot be generalized for other AM materials without taking into account other material aspects, such as void/microstructure characteristics and failure mechanism.

For instance, a study performed by Leuders et al.[32]on 316L SS, fabricated via an L-PBF system, showeddistinct fatigue behavior after HIP, as presented in Fig. 2. As it may be seen, in contrast to Ti-6Al-4V, L-PBF 316L SS in its 'HIPed' condition demonstrates lower fatigue resistance relative to itsas-built counterpart inshorter life regimes. This is due to the fact that the failure mechanism of Ti-6Al-4V is still dominated by the remaining voids after employing HIP[32], while damage evolutionin 316L SS under cyclic loading is more strongly affected by itsmonotonicstrength, which can actually be reduced through HIP [32].In addition, 316L SShas 
avery high ductility(> 50\%), and this can possibly accommodate an increased stress field imposed by defects; thus, the influence of HIP on the fatigue strength is less effective as compared to that of Ti-6Al-4V[32]. It should be noted that no further heat treatments were performed after HIP was done on either material.

The fatigue resistance of L-PBF Inconel 718 specimens [19], as presentedin Fig. 1(c), also possesses a relativelylowHCFresistance while in the HIPed condition $\left(1163{ }^{\circ} \mathrm{C} \pm 10{ }^{\circ} \mathrm{C}\right.$ and $~$ $102 \mathrm{MPa}$ for 3 hours).Analysis of the HCF fracture surfaces of L-PBF Inconel 718has revealed crack initiations from largeun-melted regions $(>100 \mu \mathrm{m})$ adjacentto the specimens' surface[19]. TheL-PBF Ti-6AL-4V investigated by Leuders et al.[27] also showed the presence of large voids (>72 $\mu \mathrm{m}$ ) after HIP, and these voids were found to serve as fatigue crack initiation sites. These findingssuggest that voidsinside AM partscannot always besuppressedby employing HIP.In fact, in addition to the parameters chosen for HIP (i.e. pressure, temperature, and time), closure of a voidis dependent on the encapsulated gas inside of it[30].

The laser-based AM process takes place inside a chamber filled with aninert, protective gas, e.g., argon, to avoid oxidization of the fabricated material at elevated temperature.Thecomplete suppression of process-sourced voidsin AM parts fabricated in inert atmosphere may be difficult to achieve given the low solubility of common inert gases in the metal matrix [30,33].Nevertheless, the HIP process can still improve the durability and HCF performance of AM partsby decreasing thesize of voids andsmoothening theirsharp angles, as well as fusing any un-melted particles. 


\section{Effects of size, geometry, and process time interval}

In AM methods, any change in the size, geometry, or numberof fabricated parts on the build platemay significantlyaffect final productproperties (micro- and macro-structural) [2,12]. Therefore, for partswith complex geometries, the possibility of achieving a homogenous microstructure and defect distribution is debatable given the current state-of-the-art in AM technology.More importantly, mechanical data as collected from small laboratory specimens may not be truly representative of those inherent to actual parts of the same material and process. Thus, establishing process-structure-property-performance relationships for variousAM materials and processes is vital for reducing uncertainty in performance of the fabricated parts.

The primary reasonfor variation in properties as a result of a change in specimen/part size or geometry is related to the thermal histories experienced during fabrication, which can be affectedbyany change in the inter-layer time interval, i.e. the amount of time taken for the laser to finish one layer and start depositing the next layer[12].The inter-layer time interval can also vary withthe number of parts fabricated on a build plate, and this is important for scenarios in which one seeks to maximize the number of parts fabricated per build operation. Therefore, even under constant laser process parameters and scanning pattern, different inter-layer time intervals is inevitable as one changes the size or number of parts on the buildplate. As a result, distinct thermal histories, and consequently, various microstructural details including grain size, phase fraction, defect size and distribution maybe obtained by varying theinter-layer time intervals[12].

The effect of inter-layer time intervals during DLD [12]and L-PBF [34]processes on the properties of fabricated samples has been recently investigated. This was achieved by varying the number of samples fabricated on a build plate [12,34],as shown in Fig. 3(a).In one set, a single cylindrical rodwas fabricated on the buildplate (single-built), as shown in Fig 3(a); while 
for the other set, multiplerods were fabricated on the buildplate together (multi-built), as shown in Fig. 3(b). As a result, the samples of each set experienceddifferent inter-layer time intervals anddistinct thermal histories (i.e. heating/cooling rates) during fabrication.

Forsingle-built 316L SS samplesfabricated via DLD,the inter-layer time intervalwas approximately $10 \mathrm{~s}$, and the multi-built samples experienced an inter-layer time interval nearly 10x as large,i.e. $\sim 100$ s[12]. Microstructural investigations revealed distinctporosity and grain size for the DLD 316L SS samples of the two sets, as presented in Fig. 3(c)[12].Samples with longer inter-layer time intervals(i.e. multi-built) contained afiner microstructure due to higher cooling/solidificationrates along each layer ( $\sim 60 \mu \mathrm{m}$ in average). Conversely, samples with shorter inter-layer time intervals (i.e. single-built)experienced lower cooling rates and higher bulk temperature, resulting in a coarser microstructure $(\sim 140 \mu \mathrm{m}$ in average)[12]. In addition, longer inter-layer time intervals were found to diminish the laser penetration depth, or heat affected zone size, due to colder, initial layer temperatures and thisimpacted the degree of previouslayer re-melting.Due to this lower laser penetration depth, previously-deposited layers displayed lack of fusion traits, as such layers could notbecome sufficiently molten toachieveeffective metallurgical bonding. This allowed the formation of un-melted regions between layers. As a result, voidswere found to be moreprevalent in the multibuiltsamplesrelative to the single-built ones, as shown in Fig. 3(c)[12].

Multi-built specimens fabricated via DLD were found to exhibit higher Vickers hardness, compressive yield, tensile yield and ultimate strength values as compared to their single-built counterparts[12]. This is attributed to the longer inter-layer time intervals utilized for the multibuilt specimens, leading to higher cooling rates, and consequently, finer microstructure. Engineering tensile stress-strain curves of DLD 316L SS for thesingle-built and multi-built sets 
are shown in Fig. 3(d)[12].It may be seen thatthe elongation to failure of the multi-built specimens is significantlylower than that of the single-built set, due to the higher level of porosity and finer microstructure. Moreover, since slight oxidization is somewhat unavoidable for the employed DLD process, oxide particleswere observed more frequently on the tensile fracture surface of multi-built specimens, as such specimens experienced longer exposure timesduring the manufacturing process, relative to the single-built ones[12].These features may also justify the observed lack of ductility for the multi-built specimens.

The authors herein have also evaluated the effect of process time intervals on fatigue behavior of DLD Ti-6Al-4V[35]. The results have demonstrated a significant difference in fatigue performance between single-built and double-built specimens in various fatigue life regimes[35]. Double-built Ti-6Al-4V specimens showed lower fatigue strength, as compared to their singlebuilt counterparts, mostly due to the presence of more voids - servingas crack initiation sites.In addition, the coarser microstructure of the single-built specimensmay have causeda higher resistance against crack propagation, by providing a more tortuous path for crack, mostly in low cycle regime[35].

A similar studysuggests that the mechanical properties of parts fabricated via L-PBF are less sensitive to variation in inter-layertime interval[34]. As shown in Fig. 4, differences in tensile and compressive strengths, as well as elongation to failure under tension, between singlebuiltand multi-builtsetsof L-PBF 17-4 PH SS are not significant[34].Relative to DLD, L-PBF can provide for significantly higher laser scanning speeds ( 10-100x faster) and lower layer thicknesses ( 10x smaller), and most importantly, the part is surrounded by powder during the build. The surrounding powder behaves as an insulator to heat transfer, and since L-PBF parts are not exposed fully to the environment during the build, the cooling rates are less surface area 
dependent. In addition, the powder feeding mechanism in L-PBF process causes an extra interlayer delay( 15 s)- dueto the time that takes to spread a new powder layer - decreasing the difference in the total inter-layer time between single-built ( 20 s) and multi-built ( 55 s) specimens.Spreadingnewpowder layer over the previously-built material also allows the accumulated heat in parts to reduce due to heat transfer with the cooler, fresh powder layer, and this results in various part assemblies having more similar thermal histories. Nevertheless, variation of lower length-scale (micro-level) properties is still likely to occur forparts fabricated via L-PBF; therefore, it can be expected that the inter-layer time interval variations during LPBFto affect the fatigue behavior, which is a more local phenomenon relative to monotonic properties.

\section{Effect of build orientation}

The orientation in which AM parts arebuilt (i.e. build orientation) may greatly affect defect directionalities (i.e. aspect ratio in shape), and thus, generates and dictates their anisotropic structural response, especially in tensile strength,elongation to failure, and fatigue resistance[11,24,29,36-39]. In addition, the anisotropy may also be resulting from changes in the thermal history during fabrication (i.e. cooling rate and cyclic re-heating from subsequent layers), which affect microstructural details (i.e. grain size, phase fraction, defect size, type and distribution, etc.)[11].

It has been found that 17-4 PH SS, fabricated via an L-PBF method in the vertical and horizontal orientations, reveal anisotropy in tensile strength, elongation to failure, and fatigue resistance, as shown in Fig. 5[11].From Fig. 5, it may be seen that horizontally-built specimens, in their as-built condition,exhibit higher monotonic tensile strength, fatigue resistance,and 
elongation to failure relative to the L-PBF parts built vertically.The L-PBF 316L SS specimens have found to also possess higher fatigue strength when built horizontally as compared to either vertically or diagonally ( $45^{\circ}$ with respect to the build plate)[40]. Other studies in the literature have reportedsimilar results, with horizontally-built specimens possessing higher tensile strength and fatigue resistance relative to those fabricated in other orientations[11,24,29,36,37,41].

Mower andLong[41] recently demonstrated higher fatigue strength forhorizontal L-PBF17-4 $\mathrm{PH}$ SS specimens as compared to diagonal specimens. Likewise,enhanced fatigue resistancewasobserved for Ti-6Al-4V specimens fabricated via either L-PBF or DLD in the horizontal orientation, as compared to their vertically-built counterparts [24,29]. These findings indicate that a part's build orientation strongly affectsits fatigue resistance; independent of the material type and manufacturing method (i.e. L-PBF or DLD).

In general, as-built AM parts inherently consist of anisotropic microstructuredue toan uneven thermal historyand directional heat transfer that the parts experienceduring fabrication [42,43]. Microstructural features, including grain size, grain morphology,and crystallographic orientation, affect the fatigue performance and failure mechanism of the part, especially pertaining to crack initiation and short crack growth.Therefore, the effects of microstructural features, as driven by thethermal history during the AM process, need to be considered for investigating the anisotropic behavior of AMparts[9].

In the absence of voids and inclusions, slip bands usually drive crack initiation in metallic materials[44]. In general, finer microstructures provide better crack initiation resistance than coarser microstructures due to higher density of slip bands - when crack initiation occurs in slip bands within grains[45].Additionally, fatigue crack initiation of textured materials is controlled by the orientation of the active slip system(s) with respect to theloading direction(s) - i.e. 
maximum shear stress [46]. For instance, higher fatigue strength has been reportedfor Ti-6Al-4V when the maximum resolved shear direction is perpendicular to basal planes, where the easiest andmost common slip systems, basal slip, reside in this alloy[47-51]. Crystallographic orientations of the adjacent grains may also act as a barrier for short crack growth [52,53]. The crack path deflection across a grain boundary is strongly influenced by the orientation relation of neighboringgrains [54]. Therefore, high-angle grain boundaries act asan effective barrier to transgranular short crack growth. Crack growth may be retarded/arrested when none of the available slip systemsare oriented closely $[45,53,55]$.

Grain size and morphology can also influenceintergranularfatigue crack growth, leading toanisotropy in fatigue performance of AM materials. Typically, coarser grains can provide better crack growth resistancedue to their larger grain boundaries, causing larger crack deflections $[17,45,56]$. In addition,anisotropic grain growth, leading to an elongated grain morphology, may affect crack growth for different loading directions. Elongated grains (i.e. columnar)typically form duringthe AM process in the direction of solidification, which tends to be near-parallel with building direction[12,16,37,57]. In case of loading being perpendicular to the building direction (i.e. the elongated direction of grains),cracks typically grow parallel to the building direction, as shown in Fig. 6(a),and therefore, they experience less deflection inthe path, leading to a lower crack growth resistance. On the other hand, a higher crack growth resistance can be expectedwhen the crack growth is perpendicular to the building direction,as shown in Fig. 6(b); such cracksexperiencea more tortuous and deflective crack path[37,56].

It is expected that post manufacturing heat treatments, such as solution/homogenizing annealing,to removethe aforementioned microstructural directionality or heterogeneities imposed bypart build orientation or directional solidification during the AM process.Inspection 
of L-PBF 17-4 PH SS microstructure has revealed no difference in grain size, grain morphology,or crystallographic orientationwithin vertically- and horizontally-built samples after heat treatment (solution annealing for $30 \mathrm{~min}$ at $\sim 1040{ }^{\circ} \mathrm{C}$ and peak-aging for 1 hour at $\sim 482$ $\left.{ }^{\circ} \mathrm{C}\right)[11]$. Although the microstructures were almost homogenized after heat treatment, theL-PBF 17-4 PH SS specimens still displayed anisotropyin tensile and fatigue strengthsas well aselongation to failure, as shown in Fig. 7[11].This figure showsengineering stress-strain curves and fully-reversed $\left(R_{\varepsilon}=-1\right)$ strain-life fatigue experimental data for L-PBF 17-4 PH SS in heat treated condition [11].Kobryn and Semiatin[24] also reported anisotropic tensile and fatigue behaviors for vertical and horizontal DLD Ti-6Al-4V after stressrelieving in vacuum for $2 \mathrm{~h}$ at $700-730^{\circ} \mathrm{C}$. These results suggest that the observed structural anisotropy in AM parts may be more influenced by defects rather than microstructure[24].

Using X-ray computed tomography (CT) and microstructural imaging, the defects within variousL-PBF 17-4 PH SS samples have been characterized, revealing the presence of large voids with high aspect ratio (ratio of the largest to the smallest overalldimension of the void). Figure 8(a) illustrates the typical porosity within the gage sectionsof horizontal and vertical LPBF 17-4 PH SS specimens, detected using X-ray CT[11]. As shown in Fig. 8(b), these voids (i.e. un-melted regions)wereirregular andslit-shaped;forming mostly between layers due to insufficient fusion or low penetration depth of laser[11]. The orientation of these voids with respect to the loading direction were found to be the main source of the structural anisotropy observed in these vertical and horizontal specimens, causing anisotropic damage evolution under various loading directions. The lower elongation to failure and fatigue strength of vertical specimens, as compared to horizontal ones, as seen in Fig. 7,is most likely due to the fact that the major axesof thesplit-shaped un-melted regionswereperpendicular to the loading axis; thus, 
providing higher stress concentration, and consequently, easier meansfor void growth and crack initiation. This is shown schematically in Fig. 8(c). For the horizontal specimens, the major axes of the un-melted regionswere parallel to the loading direction, resulting in lower stress concentrations and relatively more resistance to crack initiation[11].

Experimental evidence suggests that although the proper heat treatmentmay be able to remove structural anisotropy arising from microstructure directionality, it may not be a feasible option due to defect directionality. In this regard, the HIP process is a legitimate candidate for remedying structural anisotropies related to microstructure and defects. An investigationon the mechanical behavior of L-PBF Inconel 718 [19]revealedno microstructural (e.g., grain size/morphology, crystallographic orientation) or voids'directionality (e.g., aspect ratio in shape)within horizontally- and diagonally-built samplesafter employing HIP. The results of Kobryn and Semiatin[24]have also shown that HIP can significantly reduce the anisotropy in tensile and fatigue properties of DLD Ti-6Al-4V originating from the part's build orientation, by reducing manufacturing-inducedporosity,as well as eliminating directional porosities.These results suggest that the high temperature and pressure that occur during a typical HIP process not only homogenize the microstructureby complete recrystallization of the material[19,29,58], but may also remove or reduce directionality invoids' shape by decreasing their sharp angles $[19,24,59]$.

Although AM process parameters,such aslaser power, scan speed, layer thickness and hatching pitch,can be optimized to obtainalmost fully dense parts, as authors herein exercised for L-PBF 17-4 PH SS using immersion method(Archimedes' principle)[11], the use and accuracy ofitfor improving the structural integrity is at question. The horizontally- and vertically-built LPBF 17-4 PH SS parts, optimized for density, containedmanyvoids within their gage sections, as 
can be seen inFig. 8(a).The reason is related to the presence of slit-shaped flaws, i.e.un-melted regions, which covered a broad cross-sectional region with relatively small volume; therefore, this type of voidswas not detected via bulk density measurements byimmersion method. This indicates thatconsidering only density, as measured by immersion method, as a sole criterion for process parameter optimization may not necessarily lead to the enhanced mechanical properties of AM materials - especially their fatigue resistance[11].Considering the fact that fatigue failure is a localized structural damage,unlike failure due to static load, presence of a small irregular shaped defect/void close to surface is often enough to cause fatigue failure. However, one small void may not affect the density measurement - using immersion method -significantly.

Figure 9 shows the effect of heat treatment on fatigue behavior of vertically- and horizontallybuilt L-PBF 17-4 PH SS specimens[11]. As it can be seen, the heat treated specimens, regardless of their buildorientation, demonstrated higher fatigue strengths relative totheir as-built counterparts in LCF. Heat treatment also increased the yield and tensile strengths of both vertically- and horizontally-built specimens[11]. However, contrary to expectation, the heat treated specimens exhibited lower fatigue strength in HCF. For wrought 17-4 PH SS, the HCF strengthtypicallyincreases after conducting a similar heat treatment scheduledue primarily to an increase in tensile strength (or hardness)[60,61]. This is due to the fact thatfine, coherent precipitatesin the matrix of the heat treated material increase the strength (i.e. tensile strength or hardness), and consequently, cause more resistance to dislocation movement, which results in its enhancedresistance to crack initiation [11].However, for the AM specimens that already contained voids as large as $100 \mu \mathrm{m}$, the mechanism of crack initiation leading to HCF failure has been found to be different. 
Themoreductile behavingmaterialsare typicallyless sensitive to impurities, as such materials areaccommodating to an increased stress fieldaround their voids through a larger local plastic zone[11,17]. As a result, contrary to their wrought counterparts, heat treating theL-PBF 17-4 PH SS specimensmay not improve their fatigue resistance inhigh cycle regime inthe presence of large voids.This suggests thatthe heat treatment instructions/schedule, found optimal for wrought materials, may not necessarily improve AM parts' performance.For instance, the specific heat treatment (i.e. solutionannealing plus peak-aging), which is beneficial for HCF of wrought 17-4 PH SS, is detrimental for their L-PBF counterparts. Therefore, post-manufacturing processes, such as heat treatment, need to be designed and standardized specifically for AM parts.

\section{Effect of surface roughness}

Relative to conventionally-manufactured metallic materials, additively-manufacturedparts, in as-built condition, possess significantly higher surface roughness,mostly due topartially-melted powder existingalong their periphery. This surface roughness has proven to be beneficial for some medical applications(e.g., implants)[62,63]. For instance,the surface roughness of boneinterfacing orthopedic implants may provide better bone in-growth, and consequently, faster and more effectiveosseointegration - definedas a direct structural and functional connection between living bone and the surface of a load-carrying implant[62,63]. However, surface roughness is one of the most detrimental factors affecting the fatigueperformanceof metallic materialsunder cyclic loading[17,64]. Hence, post-manufacturing operations forimproving thedurability of AM partsare often required.This is problematic, as many AM parts are desired to be used in their asfabricated, net-shape condition, especially when they have a complex geometry. Therefore, any post-production surface treatment diminishes a major benefit of AM, i.e. the ability to produce 
complex geometriesin which conventional processing may be impracticable.It is,thus,essential to fully understand the fatigue behavior of AM parts and its dependence on surface finish.

The surface roughness of an AM partcan be affected by the type of equipment, powder size,utilized process parameters, and its build orientation[4].DLD systems typically produce rougher surfaces relative to L-PBF methods, due to their use of thicker hatching pitches and layers, as well as larger size powder.In general, the surface roughness of AM parts typicallyincreases by an increase inhatching pitch, layer thickness, or powder size [4].Build rate (i.e. laser beam energy or speed)can also affect thesurfacequality, i.e.as the build rate increases, surface quality decreases[4].

Anisotropic, distinct roughness can also existalong the surface of an AM part. For instance,for a part fabricated via L-PBFwhile oriented in a vertical incline, the overhanging side (i.e. facing downward toward the build-plate) isfound to possess a higher surface roughness relative to the contracting surface (i.e. upward facing side), as shown in Fig. 10[19,40,65]. This figure presents theX-ray CT image of a $45^{\circ}$ orientated Inconel 718 specimen, fabricated via an L-PBF method. Higher surface roughness of the overhanging sideis attributed to the more direct contact of this face with the powder bed during manufacture and in this giving rise to melt pool thermal/fluidic edge effects [19].As with defects and microstructure, the surface roughness varieswith respectto position within the part[19,39,66]. It has been found that more near-surface voids form along the downward-facing side of a part fabricated at an incline[19,66], due to melt pool thermal/fluidic edge effects while in contact with powder bed during manufacture, e.g., capillary action, heat build-up, and more[19].

Several studies in the literature have investigated the effect of post-manufacturing surface treatment (e.g., as-built, machined, polished) on the fatigue behavior of various 
materials[13,18,21,22]. Results generally indicate that reducing the surface roughness, $\mathrm{R}_{\mathrm{a}}$, by machining or polishing, will improve the fatigue resistance of AM materials, especially in the long life regime (i.e. HCF). Spiering et al. [15] showed a higher HCF strength at a stress ratio of $R_{\sigma}=0.1$ for machined $\left(\mathrm{R}_{\mathrm{a}}=\sim 5 \mu \mathrm{m}\right) \mathrm{L}-\mathrm{PBF} 316 \mathrm{~L} \mathrm{SS}$ relative to their as-built counterparts $\left(\mathrm{R}_{\mathrm{a}}=\right.$ $\sim 50 \mu \mathrm{m})$. However, thedifferences inLCFbehavior ofmachined and as-built specimens werefound to be small.Stoffregenet al. [25]also studied the effect of surface condition (as-built versusmachined) on the HCF behaviorof L-PBF 17-4 PH SS under pulsating-tension $\left(R_{\sigma}=0\right)$ loading. Their results revealeda HCF strength for machined specimens $\left(\mathrm{R}_{\mathrm{a}}=\sim 0.6 \mu \mathrm{m}\right)$ nearly twice as high as that of as-built ones $\left(\mathrm{R}_{\mathrm{a}}=\sim 14 \mu \mathrm{m}\right)$.Nevertheless, the fatigue strength of as-built L-PBF 17-4 PH SS tended to meet that of machinedone in the mid-life fatigue regime[25]. Results of Aboulkhair et al. [67] showed very close fatigue resistance for as-built $(\mathrm{Ra}=\sim 17 \mu \mathrm{m})$ and machined $\left(\mathrm{R}_{\mathrm{a}}=\sim 0.6 \mu \mathrm{m}\right)$ L-PBF AlSi10Mgspecimens under tension-tension loading condition $\left(R_{\sigma}=0.1\right)$ in both mid-life and long-life regimes.

Wycisk et al.[68] studied HCF behavior of Ti-6Al-4V fabricated via L-PBF under as-built $\left(\mathrm{R}_{\mathrm{a}}\right.$ $=\sim 12 \mu \mathrm{m})$ and polished conditions at a stress ratio of $R_{\sigma}=0.1$. Their results exhibited a significantly lower HCF strength (i.e. endurance limit) for as-built specimens (210 MPa) relative to their polished counterparts (500 $\mathrm{MPa}$ [68]. In addition, contrary to expectation, they reportedhigher scatter in the HCF region for polished specimensas compared to as-built specimens [68]. This can be explainedby differences in crack initiation mechanisms between asbuilt and polished specimens. Analysis of fatigue fracture surfacesrevealed crack initiation from surface discontinuitiesfor the as-built specimens, whereas polished specimens showed failure from both surface roughness and interior defects[68]. These results suggest that the differences in defect type, size, and location, serving as a crack initiation site for polished specimens, may 
cause scatter in HCF data.In general, the influence of surface finish on fatigue behavior of AM parts may also be affected by material type, particularly its ductility and involved failure mechanisms. Amoreductilebehaving material exhibits less sensitivity to defects, surface roughness, or any stress raiser features in the microstructure. Accordingly, different materials, or even a specific material with different post-manufacturing heat treatments, may show distinct sensitivity to surface machining -depending on crack initiation mechanisms (e.g., surface versus sub-surface).

Edward and Ramula[29] investigated the effect of surface finish (as-built versus machined) on the fatigue behavior of L-PBF Ti-6Al-4V fabricated in different build orientationsunder $R_{\sigma}=$ 0.2 loading. They reported higher surface roughness and surface tensile residual stress for the specimens fabricated in the vertical orientation $\left(\mathrm{R}_{\mathrm{a}}=\sim 38 \mu \mathrm{m}\right)$ relative to their horizontallyoriented counterparts $\left(\mathrm{R}_{\mathrm{a}}=\sim 31 \mu \mathrm{m}\right)[29]$.Therefore, it can be expected that the vertically-built specimens exhibit a larger difference between the as-built and machined conditions, asthe higher surface roughness and surface tensile residual stress are more detrimental to fatigue resistance by accelerating the crack initiationstage.However, contrary to these expectations, their results showed that the effect of surface machining on improving part's HCF resistance was more pronounced for specimens fabricated in a horizontal orientation as compared to the vertical orientation [29]. This can be explainedby considering the crack initiation mechanism as well as presence of sub-surface voids, their size and distribution.Analysis of fatigue fracture surfaces, conducted in [29], revealed the presence of large sub-surface un-melted regions ( $>100 \mu \mathrm{m})$. By machiningandremovingtheroughsurface,these sub-surface voids arebroughttothesurface of the specimens. Thus, these surface voids can still serve as a crack initiation site and affect the part's fatigue behavior. In addition, depending on the size and shape, these surface voids may be more 
detrimental than surface roughness as they can provide a higher stress concentration.Un-melted regions are more detrimental for vertically-built specimens relative to horizontally-built ones, as shown in Fig. 8, due to their wider projected area and larger stress concentration. As a result, thefatigue behavior of vertically- and horizontally-built specimens with respect to the post-AM surface machining may varybased on the characteristics of interior voids formed during fabrication.

The fatigue behavior of Inconel 718 fabricated via L-PBF has been recently investigated [19]. Experimental results haveindicated thatthe location of interior voids and thethickness of the outer layer that is removedduring machiningare important parameters when quantifying the effects of surface finish (i.e. as-built versus machined) on fatigue behavior of AM parts.In this particular study, the room-temperature uniaxial fatiguebehavior of L-PBFInconel 718 - stressrelieved, HIPed (at $1163{ }^{\circ} \mathrm{C} \pm 10{ }^{\circ} \mathrm{C}$ and $\sim 102$ MPa for 3 hours), solution treated, and aged - were investigated under as-built $\left(\mathrm{R}_{\mathrm{a}}=\sim 20 \mu \mathrm{m}\right)$ and machined $\left(\mathrm{R}_{\mathrm{a}}=\sim 2 \mu \mathrm{m}\right)$ conditions[19]. It is worth noting that for the as-built specimens (i.e. fabricated directly in their net shape configuration), the circumferential surface roughness introducederror when measuring the gage section diameter, as depicted in Fig. 11. Therefore, it is essential to consider the effective load carrying area (i.e. aggregate area) for calculating the actual applied stress and comparing the fatigue behavior of as-built and machined specimens.

The stress amplitude versus fatigue life, obtained from fully-reversed $\left(R_{\sigma}=-1\right)$ fatigue tests, of the L-PBFInconel 718 specimensin the machined and as-built conditions are shown in Fig. 12[19].It may be seen thatas-built specimens havesimilar fatigue resistance relative to their machinedcounterparts in both LCF and HCF regimes. Typically, it is expected that the as-built specimens with rougher surface condition show significantly lower fatigue resistance relative to 
machined specimens,at least inHCFregime, wherecrack initiation oftendominates the total fatigue lifetime. However, the above scenario was not observedin this study,and this is most likely due to the presence of sub-surface large voids, which werebrought to the surface by machining[19].

Analysis of the fatigue fracture surfaces revealed that surface voids ordiscontinuities were the most life-limiting features of both machined and as-built L-PBF Inconel 718 specimens, regardless of the life regime (i.e. LCF or HCF)[19]. This is due to the fact that defects at the surface can provide higher stress concentration, leading to earlier crack initiation. In addition, cracks tend to grow faster along the the free surface relative to the depth of the part [69].

The short-life and early mid-life failure mechanisms of both machined and as-built L-PBF Inconel 718 specimens were characterized with cracks initiating from multiple damage sites[19].This can be explained by the fact that the crack growth life is a larger fraction of the total fatigue life at higher stress levels (i.e. LCF), which provides an opportunityfor other cracks to initiate[70,71]. In long life fatigue regimes, large voids on the surface of machined specimens were found to always serve as crack initiation sites. In this case, the most 'severe' void near the surface controls the fatigue life of machined specimens and typically, a single, dominant crack growsto failure[19].

Multiple crack initiation sites, however, werefound on the fatigue fracture surfaces of the asbuilt specimens that failed during HCF. This is attributed to the existence of more potential fatigue crack initiation siteson the surface of as-built specimens, due to the existence of a large number of discontinuities on the specimen outersurface[19]. Accordingly, several regions with similarconditions (i.e. size, location, etc.) can serve as possible crack initiation sites. As a result, crack initiation and propagation from multiple sites were observed for as-built specimens instead 
of crack initiation and propagation from the most extreme, life-limiting void that was observed for machined specimens.However, since the effects of crack propagation and coalescence are not as significant in this regime, no major differences can be noticed in Fig. 12 for fatigue livesbetween themachined and as-built specimens at HCF[19].

The X-ray CT scans, taken from the gage section of an as-built L-PBF Inconel 718 specimen, revealed the presence of large voids along its perimeter, as can be seen in Fig. 13(a). Direct contact of the part's surface with the powder bed during manufacture may have given rise to melt pool thermal/fluidic edge effects (i.e. instabilities), leading to near-surface voids along the edges of the part. In addition, theHIP process cannot remove open voids (i.e. surface-connected voids), because these type of voids act as an extension of the specimen's surface [72]. Therefore, for asbuilt L-PBF parts, the probability of the voids being near the surfaces is higher than machined ones. These observations suggest thatthe thickness of material removed during machining may play a significant role on the fatigue behavior of post-machined AM parts.In other words, depending on the thickness of the outer layer that is trimmed away during machining, the voids may be removed or brought to the surface. As a result, fatigue behavior of machined specimens may be different based on the specimen design, as shown in Fig. 13(b).

Figure 13(b) schematically shows different specimen designs, including fabricating the near net shape specimen as well ascylindrical rod. As seen, the thickness of the outer layer that needs to betrimmed away during machining is thinner for the near net shape specimen as compared to the rod one.Accordingly, by removing a thin layerfrom the surface of a near net shape fabricated specimen,the effect of surface machining on fatigue life may not be as pronounced[19].These findings suggest that the specimen design procedure may need to be standardized for AM materials in order to obtain a better understanding of their fatigue behavior as it pertains to the 
more robust engineering of partsfabricated via AM. However, if the process/design parameters are optimized in the way that there are not any near surface voids in the as-build specimens, the thickness of the removed layer during the post-manufacturing machining process should not greatly affect the fatigue behavior.

\section{Some immediateopportunities}

Thefatigue behavior and related challenges inherent tometallic parts fabricated via laser-based AMhas been summarized and discussed; however, there are many more challenges related to the improvement of AM parts that have not been discussed in this overview, such asresidual stress, very high cycle fatigue behavior, process parameters optimization, process control, and more.Regardless, it has been clearly demonstratedthat the fatigue resistance of AM parts is typically lower than their wrought counterparts mainly due to presence of manufacturing induced defects.Furthermore,material properties obtained from laboratory specimensmay not be directly applicablefor determination ofpartperformance.

Laboratory specimens experience a thermal history unique to their own fabrication and different to that of parts. As a result,microstructural featuresand mechanical properties obtained fromlaboratory specimens and actual parts are also expected to be different.Therefore, it is essential to establishprocess-structure-property-performance relationships of AM materials in order to reduce uncertainty in predicting the performance offabricated parts. In addition, mechanical testing methods and specimen design procedures may need to be revisedto better understand the mechanical behaviorof engineering partsfabricatedvia AM.Post-manufacturing treatment protocols used for wrought materials may not be applicable for improving the 
durability of AM materials. Thus, procedures for the effective and consistent post-manufacturing treatments of wrought materials may need to be revised for AM parts.

Addressing the aforementioned challengescan only be accomplished by more fully understanding theinterrelationships among process parameters, thermal history, solidification, resultant microstructure, and mechanical behavior of AM parts, as presented schematically in Fig. 14[9].As seen, utilized process and design parameters affect the thermal history (i.e. cooling rate, thermal gradients, and cyclic reheating) of the AM part. The thermal history during fabrication governs solidification, and consequently, all the resultant microstructural details such as: grain size, morphology, and orientation; defect size, type, and distribution; residual stress, etc. Accordingly, these microstructural features dictate the structural properties, and especially the fatigue performance, of fabricated parts.

It is clear that the manymachine-to-machine and process variability cancomplicate the understanding of interrelationshipsbetween process/design parametersandultimate AM part performance. Therefore, one solution for ensuring the adoption of AM materials for application should center on predicting variation in mechanical behavior of AM parts based on their resultant microstructure. The AM process parameters for a specific material system and AM method need to be ultimately optimized based on the geometry/size of the part as well as for achieving the desired/targeted mechanical properties. In addition, improving the fatigue resistance may be possible by aligningthe bestconceivable properties of a part in accordance with the loading characteristics/directions and/or minimizing the defects in the part's critical locations with high stresses. These opportunities in additive manufacturing of better fatigue resistant materials are discussed in more details in the following sections. 


\subsection{Microstructural sensitive mechanical models}

Variations of microstructural details, resulting from AM processing conditions, cause greater uncertainty and scatter in mechanical behavior, and especiallythe fatigue resistance, of AM parts. Despitesignificant research efforts foroptimizing process parameters to fabricateAM parts with uniform microstructure [2,10], overcoming this challenge is still an open issue.Achieving a homogenous, defect free AM product immediately after its fabrication has not yet been fully demonstrated.Therefore, having the ability to accurately predict variation in mechanical behavior may accelerate the adoption of AM for a myriad of engineering applications. In this regard, a microstructural sensitive mechanical model thatcan incorporate the microstructural details, especially defect statistics (e.g., size and spacing), may be appropriate formodeling the mechanical behavior of AM parts[9]. Such a microstructure-property model provides the ability to predict damage evolutionunder loading - whethermonotonic or cyclic fatigue - basedon the microstructural details resulting from the manufacturing process.

The internal state variable (ISV) plasticity-damage model[73,74] is an example of such microstructural sensitive mechanical models and has proven to be effective in linking microstructural details(i.e. grain size and morphology as well as defects statistics) to deformation behavior of materials under tension, compression, and torsion loading conditions.This model incorporates the main steps related to damage evolution, i.e. void nucleation, growth, and coalescence to predict the monotonic stress-strain response of the material as well as its variations as affected by microstructural properties and defects statistics.

The applicabilityof the ISV plasticity-damage model to predict themonotonic tensile behavior of DLD316L SS was examined by the authors herein[75]. In this particular study[75], the effects of microstructural features,associatedwith the manufacturing process of both 'single-built' and 
'multi-built’DLD 316L SS(see Fig. 3) onstress-strain behaviorwere successfully captured usingthe ISV plasticity-damage model. Figure 15 presents thestress-straindata from tension experiments and the predictions based on the ISV plasticity-damage model for single-built and multi-built DLD 316L SS[75]. The predicted lower and upper bounds, presented in Fig. 15, indicate that the model is capable ofcapturingscatter in stress-strain experimental data(shown as error bars)using the microstructural details uniqueto each set of specimens. The ranges observed during tension experimentsforelongation tofailureswere predicted using the defects data/statistics in the fabricated material. Theranges for yield and ultimate strengthswere alsodetermined by the standard deviation of measured grain size in each set[75].

Under cyclic loading, the multi-stage fatigue (MSF) model, asintroduced byMcDowellet al. [76],can bea useful microstructuralsensitive fatigue model as it has a proven ability to capture microstructural details and to link them to fatigue behavior.The MSF model considers multiple experimentally-observed stages of fatigue damage evolution, i.e. crack incubation, small crack growth, and long crack growth.The MSF model was successfully applied to DLD316L SS [77] and DLD Ti-6Al-4V [78], as shown in Fig. 16. The fatigue behavior in these materials can be modeled based onmicrostructural features, such as grain size, porosity, void size and spacing.

This specific model (i.e. MSF model) also has the ability to provide a range of possible fatigue lives depending on the microstructural properties and defects, as presented in Fig. 16[77,78]. Analysis of fatigue fracture surfaces has revealed that fatigue cracks are mostly initiated from relatively large voids located at or near the specimens' surface [77,78]. Thus, the lower and upper boundscorrespond to the largest and smallest void diameters observedand this aids in predicting uncertaintyin thefatigueexperimental data. As seen from Fig. 16, these bounds fit the data satisfactorily, with most of the experimental data points falling within the upper and 
lower prediction bounds.More importantly, the upper bounds predicted by the MSF model arealso close to the fitted curves for wrought materials,as can be seen from Fig. 16,indicatingthat the void size is asignificant contributor to the fatigue behavior of DLD 316L SS[77,78]. In other words, the model correctly predicts the fatigue behavior of the wrought material close to the upper bound, where voids are either very small or do not even exist.

Although such microstructural sensitive fatigue models are difficult to calibrate, they are very useful for AM parts as they do not have uniform microstructural properties and defects statistics, due to variation of thermal history in different locations of the part. Therefore, it maybe worth calibrating the model once, although experimentally exhaustive, and then use it for any element/point of the part only by knowing the microstructural details (e.g., grain size and defects statistics). These models provide a meansforpredicting the mechanical behavior by linking the stress/strain (based on geometry and loading) and strength (based on microstructure and defects properties) contours.

\subsection{Design for application}

\section{Critical location(s) approach}

Developing microstructural sensitive mechanical models based on structure-property relationships of AM materials would be the first step toward minimizing costly prototyping, reducing testing, design optimization, and improving partreliability.Such models can also be complemented by using finite element analysis (FEA) to determine the critical location(s) or element(s) with higher stress/strain and possibility of fatigue failure for any part with complex geometry. As a result, a reverse design approach can be developed to determine process/design parameters based on the targeted application, geometry, and service loading, as shown in Fig. 14. 
After determining the critical location(s) and associated stress/strain for a part through FEA, the performance of the AM part may be enhanced by appropriately tuning/selecting the process and design parameters for the critical location(s) with high stresses. For the real-time controllable AM systems, defects can be minimized at critical location(s) through controllingprocess and design parameters during fabrication, as described schematically in Fig. 14 by a means of reverse engineering approach. This approachis much more time and cost efficient than controlling process for the entire part. For AM methods, lacking real-time monitoring and controlling system, the most suitable process parameters can be selected based on the critical location(s)' geometry. In this case, the local thermal histories dictatethe most appropriate process parameters for fabricating a part,with minimal defectsat critical location(s).Therefore, thermal simulations of the AM process in advance of fabrication can help in adjusting the process/design parameters to achieve the desired thermal history[79]. However, enhancing the mechanical performance by adjusting the process/design parameters, even at critical locations, requires an understanding of process-structure-property-performance relationships of AM materials and parts.

Improving the surface quality only for the critical location(s) would be an alternative approach to enhance fatigue performance of AM structural components under service loading.The need for post-manufacturing surface treatment (e.g.,machining, polishing, shotpeening, or laser shock peening) limits theappealof AM technology, which provides the ability toproduce complex geometries unachievable via conventional manufacturing methods.Hence, conducting post-manufacturing surface treatments only on the critical location(s) would be more efficient and better justified forparts manufactured by AM techniques. 


\section{Critical direction(s) approach}

Strategically aligning the relative orientation of a material's strongest plane(s) to the loading critical direction(s) in parts is another solution for improving the fatigue performance of AM parts. In other words, the inherent anisotropy of AM materials may provide a unique opportunity to improvetheir fatigue performancethroughtexture control; by matching the most critical stressing direction(s) within the partto the best properties offered by texture. This may include defining an appropriate angle between layers - linked to the grain morphology, crystallographic orientation, and voids' directionality - and loading direction.

A combination of experimental, computational, and analytical methods may be utilized to facilitate an approach, as shown schematically in Fig. 17, for designing parts with enhanced structural integrity under service loading. The left side of the "V" defines the loading requirements as stress/strain histories at the critical element(s)/location(s) dictated by the part geometry and realistic, multiaxial loading; while the right side of the "V" describes the design approach to fabricate materials with the desired microstructure, including grain size and orientations as well as defects distribution and directions.

The multiaxial stresses in critical elements of components and structures not only arise from multidirectional loading, stress concentrations, or residual stresses[80], but also from the heterogeneity of the microstructure, specifically for AM materials. Therefore, it is essential to account for the cyclic multiaxial stresses/strains in design by a means of an appropriate multiaxial fatigue model.Multiaxial loadings can be categorized as either in-phase (IP) or out-ofphase (OP); for IP or proportional loading, the ratio of torsional to axial loading and its principal directions remain fixed;however, under OP or non-proportional loading, principal directions, and consequently, maximum shear directions rotate in time. 
Investigations of cracking behavior under multiaxial loading indicate that cracks usually nucleate on preferred planes within the material, as presented in Fig.18 for 1050 normalized steel under IP loading[60].Although the preferred orientation depends on the material and the state of loading, it can be seen from Fig. 18 that such orientation is not random. This suggests that the preferred plane(s) for cracks can be detected based on damage distribution on all planes within the material, assuming isotropic and homogenous,using an appropriate multiaxial damage parameter.

Damage observations suggest critical plane approaches, which reflect the physical mechanismof the fatigue damage process, are most reliable and robust for multiaxial fatigue life estimations[80]. These approaches consider specific plane(s) within the material with maximum fatigue damage as the critical plane(s).The Fatemi-Socie (FS) model[81] is an example of a critical plane approach for shear damage materials, as presented by Equation (1):

$$
\frac{\Delta \gamma_{\max }}{2}\left(1+k \frac{\sigma_{n, \max }}{\sigma_{y}}\right)=C
$$

where $\sigma_{\mathrm{y}}$ is the material monotonic yield stress and $k$ is the material constant, which can be found by fitting uniaxial fatigue data to the torsion fatigue data, $\Delta \gamma_{\max } / 2$ is the maximum shear strain amplitude and $\sigma_{\mathrm{n}, \max }$ is the normal stress acting on the plane of maximum shear strain.

An example of damage distribution with plane orientation for IP and $90^{\circ} \mathrm{OP}$ axial-torsion loading with the same equivalent strain based on the FS parameter is shown in Fig.19[80]. As seen, a higher damage valuefor OP loadingresults in ashorter fatigue life as compared to IP loading. More importantly, the maximum damage values, based on FS damage parameter, occur along the $115^{\circ}$ and $0^{\circ}$ planes for IP and OP loadings, respectively -in agreement with experimental observation for cracking orientations, shown in Fig. 19. Results indicate thatcracks 
nucleate and grow on the plane(s) with the highest damage values, depending on the material and the state of loading, rather than random orientation.

It should be noted that this may not be the case for AM materials considering the fact that they are often anisotropic due to their texture and defects' directionality, respectively, resulting from the presence of elongated grain morphology and inter-layer slit-shaped voids. For AM materials, which are not necessarily homogeneous and isotropic, a relative critical plane approach needs to be defined to account for both material and loading critical planes. In this case, the relative critical plane approach can be utilized for the reverse engineering, based on Fig. 17, to align the strongest material plane with the loading critical plane, and the weakest material plane withthe direction which experiencesminimum damage from loading.

The multiaxial fatigue life of AM partscan possiblybe improved by development of directionally processed materials in which the best property/texture directionsare aligned with the most critical loading plane under service loading. By performing analytical critical plane searches in the macroscale, the directions with high risk of fatigue failure under multiaxial loading can be determined. A microstructural sensitive fatigue model can then relate the damage values in different directions to microstructural properties (i.e. grain morphology, crystallographic orientation, and defect orientation) for the intended service loading and the required life cycle. Thereupon,the obtained relationship may be utilized to adjust the process and design parameters to control the thermal history for desired microstructure (grain morphology, crystallographic orientation, and defects' directionality), as shown in Fig. 17, to move the material's critical plane (i.e. weak plane) from the loading critical plane. The required thermal history, including cooling and solidification rates and heat flux direction, can also be simulated 
for predicting and/or controlling appropriate process/design parameters during or before AM, as needed.

For instance, as seen from Fig. 19, if loading is IP, the strongest plane should be aligned with $\sim 5^{\circ}$ or $\sim 115^{\circ}$ planes and the weakest aligned with $\sim 65^{\circ}$ or $\sim 155^{\circ}$ planes. Similarly, if the

loading is OP, the strongest plane should be aligned with $0^{\circ}$ plane and the weakest plane to fall somewhere within $50^{\circ}$ to $130^{\circ}$ range. These techniques, including critical locations and directions as well as microstructural sensitive mechanical models, may provide a means of fabricating more fatigue resistant AM parts until fabrication of defect free products can be fully achieved.

\section{Summary}

While AM continues to demonstrate potential for full-scale production of customized and/or complex parts, the mechanical behavior, and thus, trustworthiness of these partsis not yet well understood. This creates a challenge for AM technology to be fully adopted in various engineering applications such as aerospace, automotive, and biomedical. To overcome this challenge, the process-structure-property-performance relationships for various AM processes (e.g., laserpowder bed fusion and direct laser deposition) and material systems must be established. Since the fabrication parameters (process) of AM parts affecttheir microstructure (structure), which dictatesthe mechanical behavior (property)and the part performance, it is imperative that all of these phases be taken into consideration.

Despite numerous experimental research effortsfocused on characterizing the fatigue behavior of AM metals over the past decade, more research is required to enable more accurate and reliable fatigue life estimationmethodologies for AM parts. This particular problem is challenging and demands standardized approaches and measurement techniques.This overview 
paper has discussed several important ongoing challenges related to the fatigue of AM materials. Some possible,immediate solutions have been also presentedas a means to provide insights into overcoming some ofthe challenges related to the structural integrity of AM parts.

Fatigue and durability evaluation areamong the major challenges against widespread adoption of AM parts. In general, damage evolutionof metallic AM materials under cyclic loading conditions is directly affected by impuritiessourced from the AM process itself. Among the many different sources of damage evolution under cyclic loadings, voids are the majorlife limiting factor and the most dominant mechanism forfatigue crackinitiation in AM metals.Variations in location, shape, and size of voids are found to be the main reason for the large scatter in theAMfatigue data. The HIP process can be used to improve the durability and HCF performance of AM parts by fusing un-melted particles, decreasing the voids size andsmoothening their sharp angles, and evenclosing some voids. However, it should be noted that employing the HIP process in order to improve the fatigue resistancemay notnecessarily leadto the same outcomefor differentAM materials. In addition to the parameters chosen for HIP (i.e. pressure and temperature), material's microstructure, associated failure mechanism, void location, and the encapsulated gas inside of the voids play important roles.

Any change in the size, geometry, or number of fabricated parts on the build plate may significantly affect the inter-layer time intervals and thermal dissipation during AM process. The experienced thermal history, and consequently, the resultant microstructureand mechanicalproperties of the fabricated parts strongly depend on their size andgeometry. Therefore, due to variations inthermal histories,specimen properties may not be directly applicable todetermine/predict the partperformance. In addition,for a partwith complex 
geometry, a homogenous microstructure and defect distribution is hard to achieve via current laser-based AM methods.

The build orientation of AM partscan generate anisotropic structural response, especially in fatigue behavior. This is attributed to the microstructure (i.e. grain morphology and crystallographic orientation)and defects' directionality (i.e. distinctdimensions of the void in different planes). High temperature and pressure during the HIP process maysignificantly reduce the anisotropy instructural properties of AM parts,imposed by build orientation,via homogenizing the microstructurethrough complete recrystallization of the material, as well as removing thedirectionality invoids' shape by smoothening their sharp angles.

Comparing the results of variousstudies suggests that the influence of surface finish on fatigue behavior of materials may also be affected by material type, particularly its ductility and involved failure mechanisms. In addition, voids' characteristics - especially their locations andthe thickness of the removed surface during machining may play significant roles on the fatigue behavior of machined AM parts.Depending on the thickness of the outer layer that is trimmed away during machining, the voids may be removed or brought to the surface. Thus, fatigue behavior of machined specimens may be different based on the specimen design.

Mechanical testing methods, design procedures, standards, etc. may need to be revised for AM materials. Difficulty of relating specimen properties to the part performance, due to different thermal history, also needs to be addressed in the mechanical testing methods and design procedures. In addition, the structural integrity of AM parts may not necessarily improve followingthe heat treatment schedule found effectivefor wrought materials, due to the unique fatigue failure mechanisms of AM metallic parts. Therefore, post-manufacturing processes (e.g., heat treatment) also need to be developed specifically for AM parts. 
Although microstructural sensitive mechanical models are difficult to calibrate, they may be suitable for AMparts, as they possess variations in microstructural properties and defects statistics, resulting from unique thermal histories experienced at different locations within a part. Providing the ability to predict the variation in mechanical behavior based on themicrostructural details, such models may be beneficialfor reducingprototype testing,as well as improving the part'sreliabilityand design optimization. Microstructural sensitive mechanical models can also be complemented by using finite element analysis (FEA) to determine the critical location(s) with high probability for fatigue failure. Thereupon, enhancing thefatigue resistance of AM parts may be more economically possible by improving the surface quality and minimizing defects only in these critical location(s).

In addition, turning the weak plane in the material (i.e. material critical direction)away from the loading critical direction in the component may be another solution for improving fatigue performance of AM parts, considering their anisotropic and nonhomogeneous properties. By determining the directions with high risk of fatigue failure under the intended service loading, appropriate microstructural and defect properties, in particular orientation, can be identified to tolerate the loading by a means of a microstructural sensitive fatigue model. Finally,the obtained relationship may be utilized to adjust the process and design parameters to control the thermal history for achieving the desired microstructural and defects' directionalities. Again, this requires an understanding of process-structure-property-performance relationships of AM materials.

\section{Acknowledgement}


This material is based upon work supported by the National Science Foundation under Grant No. 1657195. 


\section{References}

[1] ASTM. ASTM Standard F2792-12a: Standard Terminology for Additive Manufacturing Technologies. 2012.

[2] Thompson SM, Bian L, Shamsaei N, Yadollahi A. An Overview of Direct Laser Deposition for Additive Manufacturing; Part I: Transport Phenomena, Modeling, and Diagnostics. Addit Manuf 2015;8:36-62.

[3] Selcuk C. Laser Metal Deposition for Powder Metallurgy Parts. Powder Metall 2011;54:94-9.

[4] Frazier WE. Metal Additive Manufacturing: A Review. J Mater Eng Perform 2014;23:1917-28.

[5] Lott P, Schleifenbaum H, Meiners W, Wissenbach K, Hinke C, Bültmann J. Design of an Optical system for the In Situ Process Monitoring of Selective Laser Melting (SLM). Phys Procedia 2011;12:683-90.

[6] Emelogu A, Marufuzzaman, M., Thompson SM, Shamsaei N, Bian L. Additive Manufacturing of Biomedical Implants: A Feasibility Assessment via Supply-Chain Cost Analysis. Addit Manuf 2016;11:97-113.

[7] Levy G, Schindel R, Kruth J. Rapid Manufacturing and Rapid Tooling with Layer Manufacturing (LM) Technologies, State of the Art and Future Perspectives. CIRP Ann Technol 2003;2:589-609.

[8] Murr LE, Gaytan SM, Medina F, Lopez H, Martinez E, Machado BI, et al. NextGeneration Biomedical Implants Using Additive Manufacturing of Complex, Cellular and Functional Mesh Arrays. Philos Trans R Soc A Math Phys Eng Sci 2010;368:1999-2032.

[9] Shamsaei N, Yadollahi A, Bian L, Thompson SM. An Overview of Direct Laser 
Deposition for Additive Manufacturing; Part II: Mechanical Behavior, Process Parameter Optimization and Control. Addit Manuf 2015;8:12-35.

[10] Aboutaleb A, Bian L, Elwany A, Shamsaei N, Thompson S, Tapia G. Accelerated Process Optimization for Laser-Based Additive Manufacturing by Leveraging Prior Studies. IE Trans 2016. doi:10.1080/0740817X.2016.1189629.

[11] Yadollahi A, Shamsaei N, Thompson MS, Elwany A, Bian L. Effects of Building Orientation and Heat Treatment on Fatigue Behavior of Selective Laser Melted 17-4 PH Stainless Steel. Int J Fatigue 2017; 94: 218-35.

[12] Yadollahi A, Shamsaei N, Thompson SM, Seely D. Effects of Process Time Interval and Heat Treatment on the Mechanical and Microstructural Properties of Direct Laser Deposited 316L Stainless Steel. Mater Sci Eng A 2015;644:171-83.

[13] Daniewicz SR, Shamsaei N. An Introduction to the Fatigue and Fracture Behavior of Additive Manufactured Parts. Int J Fatigue 2017; 94: 167.

[14] Bian L, Thompson SM, Shamsaei N. Mechanical Properties and Microstructural Features of Direct Laser Deposited Ti-6Al-4V. JOM 2015;67:629-38.

[15] Spierings AB, Starr TL, Wegener K. Fatigue Performance of Additive Manufactured Metallic Parts. Rapid Prototyp J 2013;19:88-94.

[16] Trosch T, Strößner J, Völkl R, Glatzel U. Microstructure and Mechanical Properties of Selective Laser Melted Inconel 718 Compared to Forging and Casting. Mater Lett 2016;164:428-31.

[17] Stephens RI, Fatemi A, Stephens RR, Fuchs HO. Metal Fatigue in Engineering, 2nd Edition. Wiley 2000.

[18] Sterling A, Torries B, Shamsaei N, Thompson SM, Seely DW. Fatigue Behavior and 
Failure Mechanisms of Direct Laser Deposited Ti-6Al-4V. Mater Sci Eng A 2016;655:100-12.

[19] Yadollahi A, Shamsaei N, Wells DN, Daniewicz SR. Fatigue Behavior and Failure Analysis of Additive Manufactured Inconel 718 Superalloy. Submittedfor publicaiton.

[20] Halford GR. Fatigue and Durability of Structural Materials. ASM International; 2006.

[21] Ma X, Duan Z, Shi H, Murai R, Yanagisawa E. Fatigue and Fracture Behavior of NickelBased Superalloy Inconel 718 up to the Very High Cycle Regime. J Zhejiang Univ Sci A 2010;11:727-37.

[22] Leybold HA. Axial-Load Fatigue Tests on 17-7 PH Stainless Steel Under ConstantAmplitude Loading. NASA Tech Note 199802282731960.

[23] Carrion P, Shamsaei N. Strain-Based Fatigue Data for Ti-6Al-4V ELI Under FullyReversed and Mean Strain Loads. Data Br 2016;7:12-5.

[24] Kobryn PA, Semiatin SL. Mechanical Properties of Laser-Deposited Ti-6Al-4V. Solid Free Fabr Proceedings Austin 2001:179-86.

[25] Stoffregen HA, Butterweck K, Eberhard Abele. Fatigue Analysis in Selective Laser Melting: Review and Investigation of Thin-Walled Actuator Housings. Solid Free. Fabr. Symp., 2013, p. 635-50.

[26] Bagheri A, Mahtabi M, Shamsaei N. Fatigue Behavior and Cyclic Deformation of Additive Manufactured NiTi. Submitt for publicaiton.

[27] Leuders S, Vollmer M, Brenne F, Tröster T, Niendorf T. Fatigue Strength Prediction for Titanium Alloy TiAl6V4 Manufactured by Selective Laser Melting. Metall Mater Trans A 2015;46:3816-23.

[28] Mahtabi MJ, Shamsaei N, Mitchell M. Fatigue of Nitinol: The State-of-the-Art and 
Ongoing Challenges. J Mech Behav Biomed Mater 2015;50:228-54.

[29] Edwards P, Ramulu M. Fatigue Performance Evaluation of Selective Laser Melted Ti6Al-4V. Mater Sci Eng A 2014;598:327-37.

[30] Leuders S, Thöne M, Riemer A, Niendorf $\mathrm{T}$, Tröster $\mathrm{T}$, Richard $\mathrm{H}$ a., et al. On the Mechanical Behaviour of Titanium alloy TiAl6V4 Manufactured by Selective Laser Melting: Fatigue Resistance and Crack Growth Performance. Int J Fatigue 2013;48:300-7.

[31] Kasperovich G, Hausmann J. Improvement of Fatigue Resistance and Ductility of TiAl6V4 Processed by Selective Laser Melting. J Mater Process Technol 2015;220:202_14.

[32] Leuders S, Lieneke T, Lammers S, Tröster T, Niendorf T. On the Fatigue Properties of Metals Manufactured by Selective Laser Melting - The Role of Ductility. J Mater Res 2014;29:1911-9.

[33] Boom R, Kamperman AA, Dankert O, Veen A. Argon Solubility in Liquid Steel. Metall Mater Trans B 2000;31:913-9.

[34] Mahmoudi M, Elwany A, Yadollahi A, Thompson S, Bian L, Shamsaei N. Mechanical Properties and Microstructural Characterization of Selective Laser Melted 17-4 PH Stainless Steel. Rapid Prototyp J 2016.

[35] Torries B, Shao S, Shamsaei N, Thompson S. Effect of Inter-Layer Time Interval on the Mechanical Behavior of Direct Laser Deposited Ti-6Al-4V. Solid Free. Fabr. Proc., 2016.

[36] Nicoletto G. Anisotropic High Cycle Fatigue Behavior of Ti-6Al-4V Obtained by Powder Bed Laser Fusion. Int J Fatigue 2016. doi:10.1016/j.ijfatigue.2016.04.032.

[37] Simonelli M, Tse YY, Tuck C. Effect of the Build Orientation on the Mechanical Properties and Fracture Modes of SLM Ti-6Al-4V. Mater Sci Eng A 2014;616:1-11. 
[38] Niendorf T, Leuders S, Riemer A, Richard HA, Tröster T, Schwarze D. Highly Anisotropic Steel Processed by Selective Laser Melting. Metall Mater Trans B 2013;44:794-6.

[39] Li P, Warner DH, Fatemi A, Phan N. Critical Assessment of the Fatigue Performance of Additively Manufactured Ti-6Al-4V and Perspective for Future Research. Int J Fatigue J 2016;85:130-43.

[40] Shrestha R, Simsiriwong J, Shamsaei N, Thompson N, Bian L. Effect of Build Orientation on the Fatigue Behavior of Stainless Steel 316L via a Laser-Based Power Bed Fusion Process. Solid Free. Fabr. Proc., 2016.

[41] Mower TM, Long MJ. Mechanical Behavior of Additive Manufactured, Powder-Bed Laser-Fused Materials. Mater Sci Eng A 2015;651:198-213.

[42] Zhang D, Niu W, Cao X, Liu Z. Effect of Standard Heat Treatment on the Microstructure and Mechanical Properties of Hot Isostatically Pressed Superalloy Inconel 718. Mater Sci Eng A 2015;644:32-40.

[43] Carter LN, Martin C, Withers PJ, Attallah MM. The Influence of the Laser Scan Strategy on Grain Structure and Cracking Behaviour in SLM Powder-Bed Fabricated Nickel Superalloy. J Alloys Compd 2014;615:338-47.

[44] Pilchak AL, Bhattacharjee A, Williams REA, Williams JC. The Effect of Microstructure on Fatigue Crack Initiation in Ti-6Al-4V. ICF12, vol. 2, 2013, p. 1-10.

[45] Bantounas I, Lindley TC, Rugg D, Dye D. Effect of Microtexture on Fatigue Cracking in Ti-6Al-4V. Acta Mater 2007;55:5655-65.

[46] Evans W, Jones J, Whittaker M. Texture Effects under Tension and Torsion Loading Conditions in Titanium Alloys. Int J Fatigue 2005;27:1244-50. 
[47] Bache MR. Processing Titanium Alloys for Optimum Fatigue Performance. Int J Fatigue 1999;21:105-11.

[48] Sinha V, Mills MJ, Williams JC, Spowart JE. Observations on the Faceted Initiation Site in the Dwell-Fatigue Tested Ti-6242 Alloy: Crystallographic Orientation and Size Effects. Metall Mater Trans A 2006;37:1507-18.

[49] Sackett E, Germain L, Bache M. Crystal Plasticity, Fatigue Crack Initiation and Fatigue Performance of Advanced Titanium Alloys. Int J Fatigue 2007;29:2015-21.

[50] Peters M, Gysler A, Lotjering G. Influence of Texture on Fatigue Properties of Ti-6AI-4V $1984 ; 15$.

[51] Bantounas I, Dye D, Lindley TC. The Effect of Grain Orientation on Fracture Morphology During High-Cycle Fatigue of Ti-6Al-4V. Acta Mater 2009;57:3584-95.

[52] Hall JA. Fatigue Crack Initiation in Alpha-Beta Titanium Alloys 1998;19:23-37.

[53] Zhai T, Wilkinson AJ, Martin JW. A Crystallographic Mechanism for Fatigue Crack Propagation through Grain Boundaries. Acta Mater 2000;48:4917-27.

[54] Jiang XP, Man C-S, Shepard MJ, Zhai T. Effects of Shot-Peening and Re-Shot-Peening on Four-Point Bend Fatigue Behavior of Ti-6Al-4V. Mater Sci Eng A 2007;468470:137-43.

[55] Pilchak AL, Williams RE a., Williams JC. Crystallography of Fatigue Crack Initiation and Growth in Fully Lamellar Ti-6Al-4V. Metall Mater Trans A 2009;41:106-24.

[56] Riemer A, Leuders S, Thöne M, Richard HA, Tröster T, Niendorf T. On the Fatigue Crack Growth Behavior in 316L Stainless Steel Manufactured by Selective Laser Melting. Eng Fract Mech 2014;120:15-25.

[57] Konečná R, Kunz L, Nicoletto G, Bača A. Fatigue Crack Growth Behavior of Inconel 718 
Produced by Selective Laser Melting. Konečná Alii, Frat Ed Integrità Strutt 2016;35:3140.

[58] Chang SH. In situ TEM Observation of $\gamma^{\prime}, \gamma^{\prime \prime}$ and $\delta$ Precipitations on Inconel 718 Superalloy Through HIP Treatment. J Alloys Compd 2009;486:716-21.

[59] Zhang YP, Yuan B, Zeng MQ, Chung CY, Zhang XP. High Porosity and Large Pore Size Shape Memory Alloys Fabricated by Using Pore-Forming Agent (NH4HCO3) and Capsule-Free Hot Isostatic Pressing. J Mater Process Technol 2007;192-193:439-42.

[60] Shamsaei N, Fatemi A. Effect of Hardness on Multiaxial Fatigue Behaviour and Some Simple Approximations for Steels. Fatigue Fract Eng Mater Struct 2009;32:631-46.

[61] Wu J, Lin C. Tensile and Fatigue Properties of 17-4 PH Stainless Steel at High Temperatures. Metall Mater Trans A 2002;33:1715-24.

[62] Anil S, Anand PS, Alghamdi H, Jansen JA. Dental Implant Surface Enhancement and Osseointegration. InTech Open Access Publ 2011:83-108.

[63] Shalabi MM, Gortemaker A, Hof MA Van. Surface Roughness and Bone Healing: A Systematic Review. J Dent Res 2006;85:496-500.

[64] Kovoacevic R, Jamshidinia M, Kong F. The Numerical Modeling of Fatigue Properties of a Bio-Compatible Dental Implant Produced by Electron Beam Melting(EBM). Proceeding Solid Free. Fabr. Symp., 2013, p. 791-804.

[65] Fox JC, Moylan SP, Lane BM. Effect of Process Parameters on the Surface Roughness of Overhanging Structures in Laser Powder Bed Fusion Additive Manufacturing. Procedia CIRP 2016;45:131-4.

[66] Beretta S, Romano S. A Comparison of Fatigue Strength Sensitivity to Defects for Materials Manufactured by AM or Traditional Processes. Int J Fatigue 2016. 
doi:10.1016/j.ijfatigue.2016.06.020.

[67] Aboulkhair NT, Maskery I, Tuck C, Ashcroft I, Everitt NM. The Microstructure and Mechanical Properties of Selectively Laser Melted AlSi10Mg: the Effect of a Conventional T6-Like Heat Treatment. Mater Sci Eng A 2016;104:174-82.

[68] Wycisk E, Solbach A, Siddique S, Herzog D, Walther F, Emmelmann C. Effects of Defects in Laser Additive Manufactured Ti-6Al-4V on Fatigue Properties. Phys Procedia 2014;56:371-8.

[69] Xie W, Yang H, Su X, Huang Q. Numerical Simulation of Fatigue Crack Growth of Surface Crack. ISMME, 2014, p. 56-61.

[70] Shamsaei N. Multiaxial Fatigue and Deformation Including Non-Proportional and Variable Amplitude Loading Effects. University of Toledo, 2010.

[71] Shamsaei N, Fatemi A. Small Fatigue Crack Growth Under Multiaxial Stresses. Int J Fatigue 2014;58:126-35.

[72] Atkinson H V., Davies. S. Fundamental Aspects of Hot Isostatic Pressing: An Overview. Metall Mater Trans A 2000;31:2981-3000.

[73] Bammann DJ, Aifantis EC. A Damage Model for Ductile Metals. Nucl Eng Des 1989;116:355-62.

[74] Bammann DJ. An Internal Variable Model of Viscoplasticity. Int J Eng Sci 1984;22:1041-53.

[75] Yadollahi A, Shamsaei N, Hammi Y, Horstemeyer MF. Quantification of Tensile Damage Evolution in Additive Manufactured Austenitic Stainless Steels. Mater Sci Eng A 2016;657:399-405.

[76] McDowell DL, Gall K, Horstemeyer MF, Fan J. Microstructure-Based Fatigue Modeling 
of Cast A356-T6 Alloy. Eng Fract Mech 2003;70:49-80.

[77] Xue Y, Pascu A, Horstemeyer MF, Wang L, Wang PT. Microporosity Effects on Cyclic Plasticity and Fatigue of LENS ${ }^{\mathrm{TM}}$-Processed Steel. Acta Mater 2010;58:4029-38.

[78] Torries B, Sterling AJ, Shamsaei N, Thompson SM, Daniewicz SR. Utilization of a Microstructure Sensitive Fatigue Model for Additively Manufactured Ti-6Al-4V. Rapid Prototyp 2016;22:817-25.

[79] Masoomi M, Gao X, Thompson SM, Shamsaei N, Bian L, Elwany A. Modeling, Simulation and Experimental Validation of Heat Transfer during Selective Laser Melting. ASME/IMECE, 2015.

[80] Fatemi A, Shamsaei N. Multiaxial fatigue: An Overview and Some Approximation Models for Life Estimation. Int J Fatigue 2011;33:948-58.

[81] Fatemi A, Socie DF. A Critical Plane Approach to Multiaxial Fatigue Damage Including out-of-Phase Loading. Fatigue Fract Eng Mater Struct 1988;11:149-65.

[82] Strizak JP, Tian H, Liaw PK, Mansur LK. Fatigue Properties of Type 316LN Stainless Steel in Air and Mercury. J Nucl Mater 2005;343:134-44. 


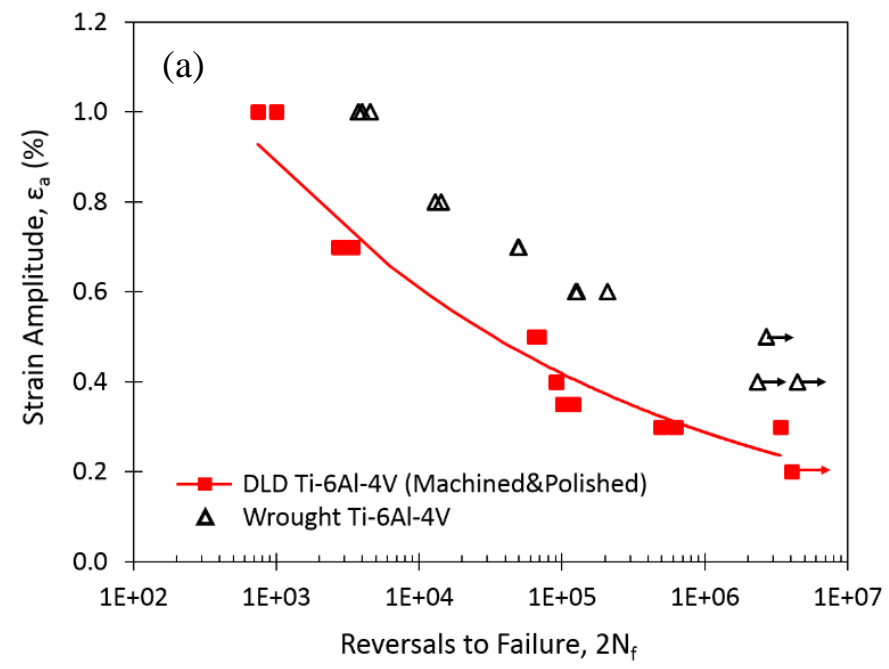

(d)
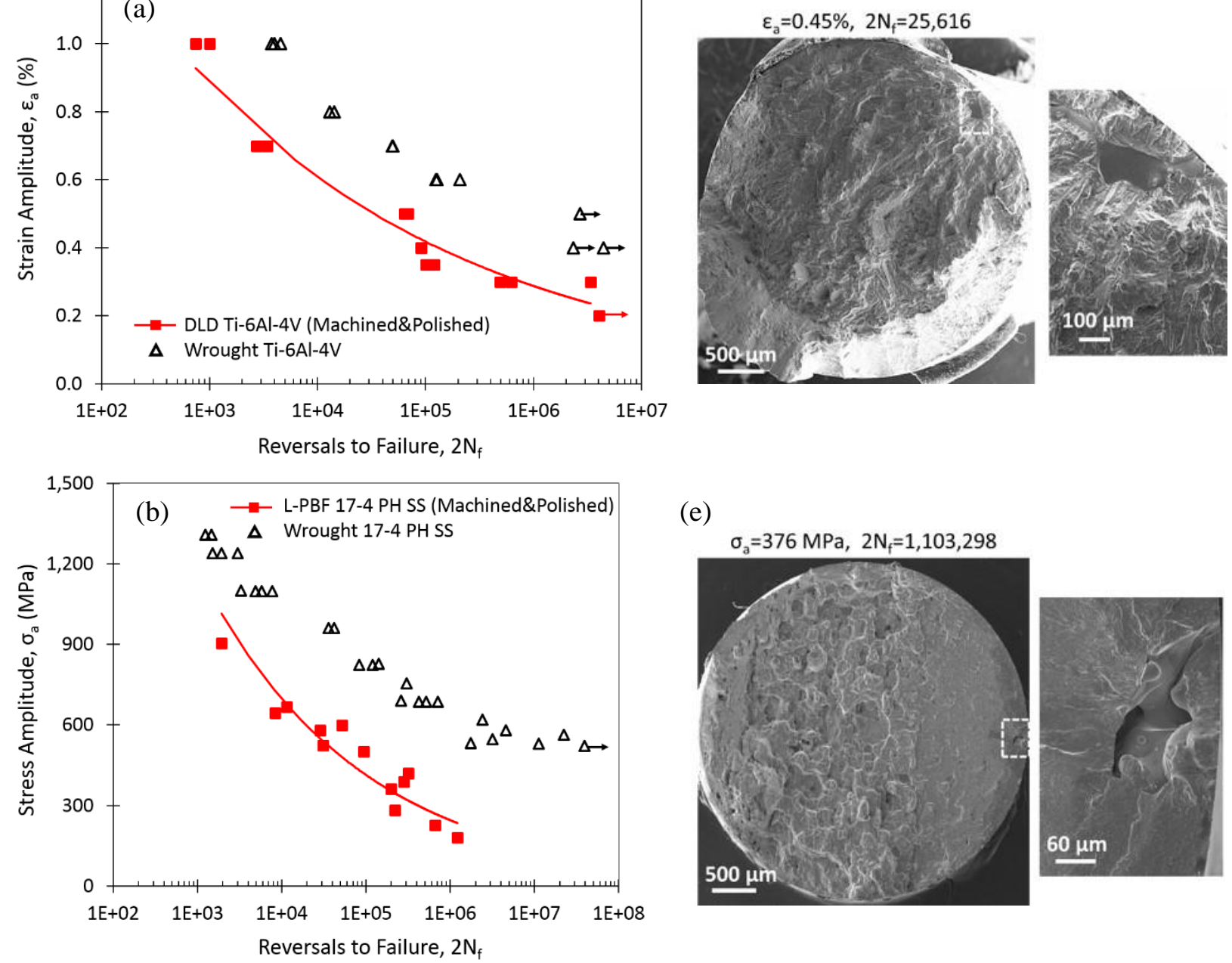

(e)
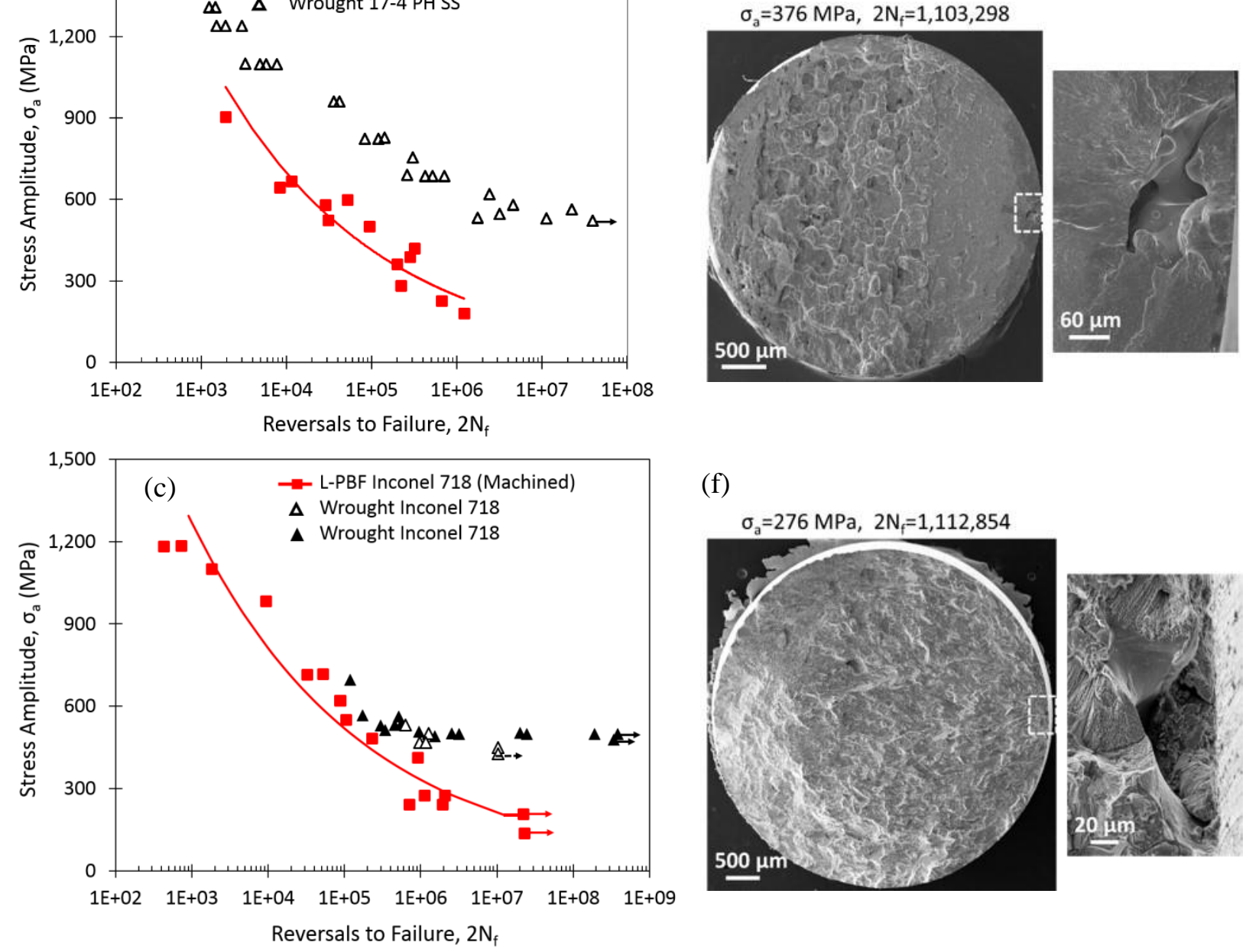

(f)
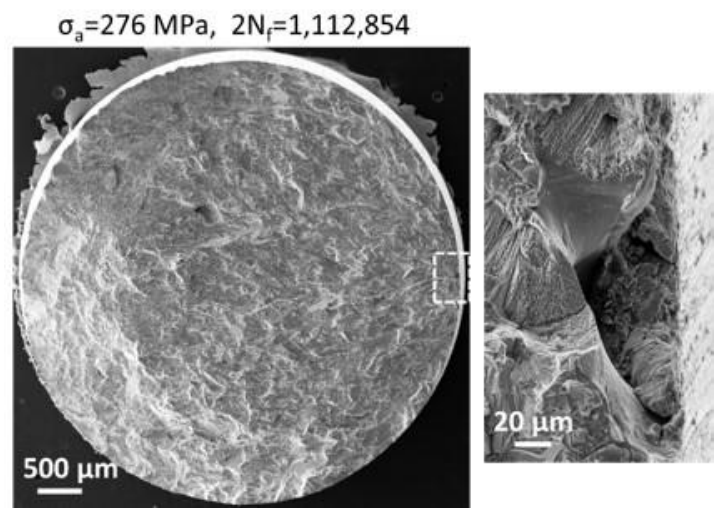

Fig. 1. Comparison of fully-reversed uniaxial fatigue data of (a) DLD Ti-6Al-4V [18], (b) L-PBF 17-4 PH SS [11], and (c) L-PBF Inconel 718 [19] to wrought materials [20-23], at room temperature. Fatigue fracture surfaces and crack initiation sites of (d) DLD Ti-6Al-4V [18], (e) L-PBF 17-4 PH SS [11], and (f) L-PBF Inconel 718 [19] specimens. 


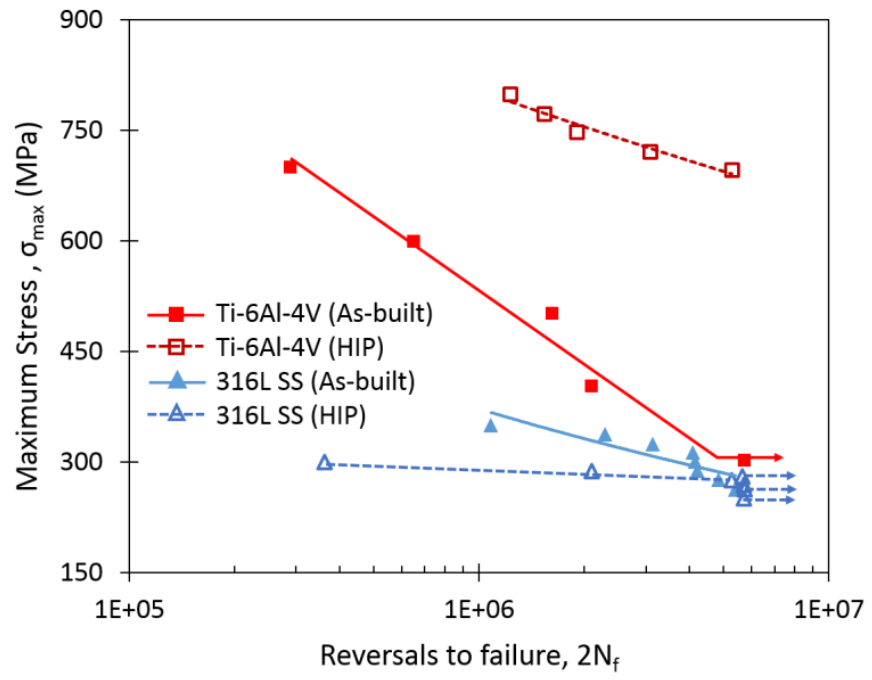

Fig. 2. Comparison of fully-reversed $\left(R_{\sigma}=-1\right)$ fatigue stress-life data for L-PBF Ti-6Al-4V and L-PBF 316L SS in as-built and HIP conditions [32]. 

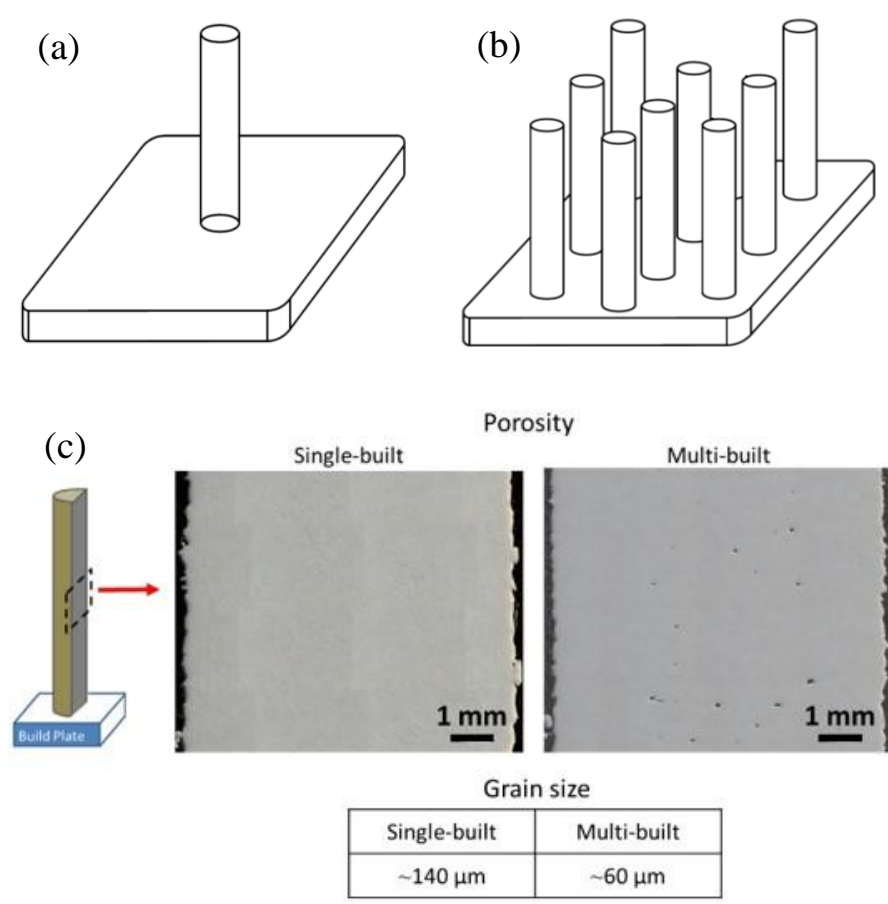

(d)

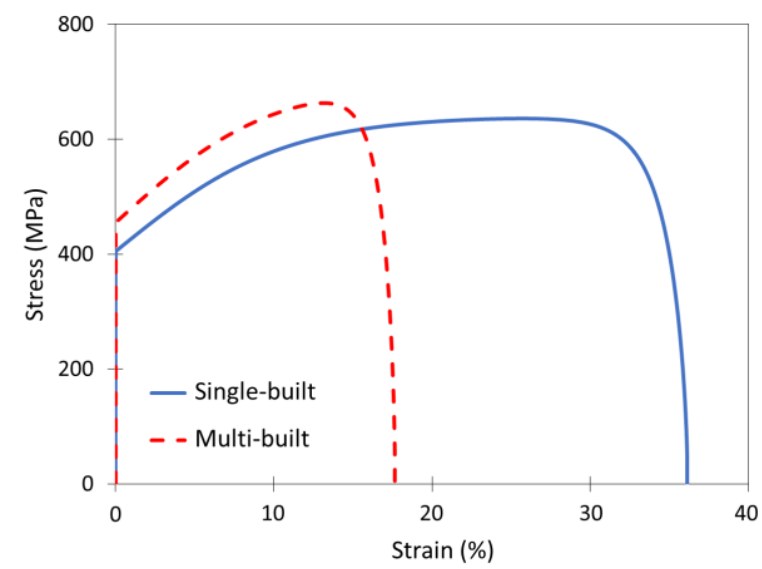

Fig. 3. Schematic of fabricated samples with different inter-layer time intervals including (a) single-built and (b) multi-built, (c) porosity distribution and measured grain size for single-built and multi-built samples at the middle region [12] and (d) engineering tensile stress-strain curves of DLD 316L SS for single-built and multi-built specimens [12]. 


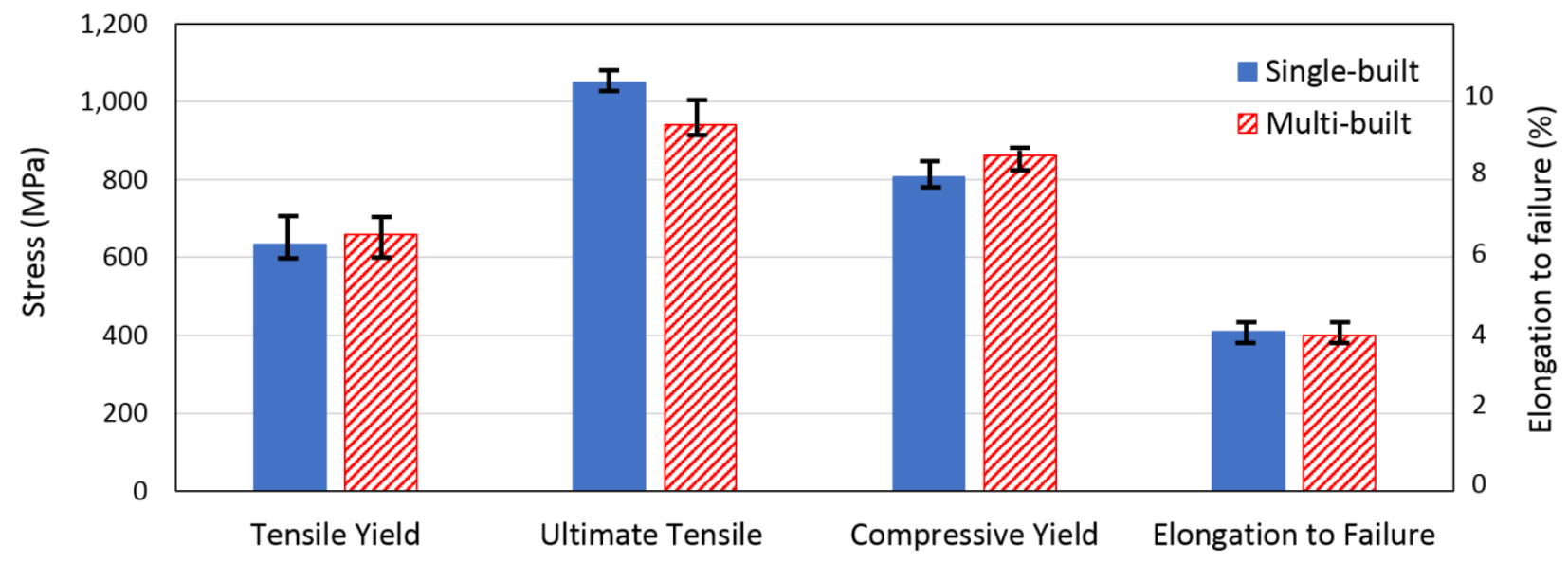

Fig. 4. Comparison of tensile and compressive strengths as well as elongation to failure for LPBF 17-4 PH SS in single-built and multi-built conditions [34]. 

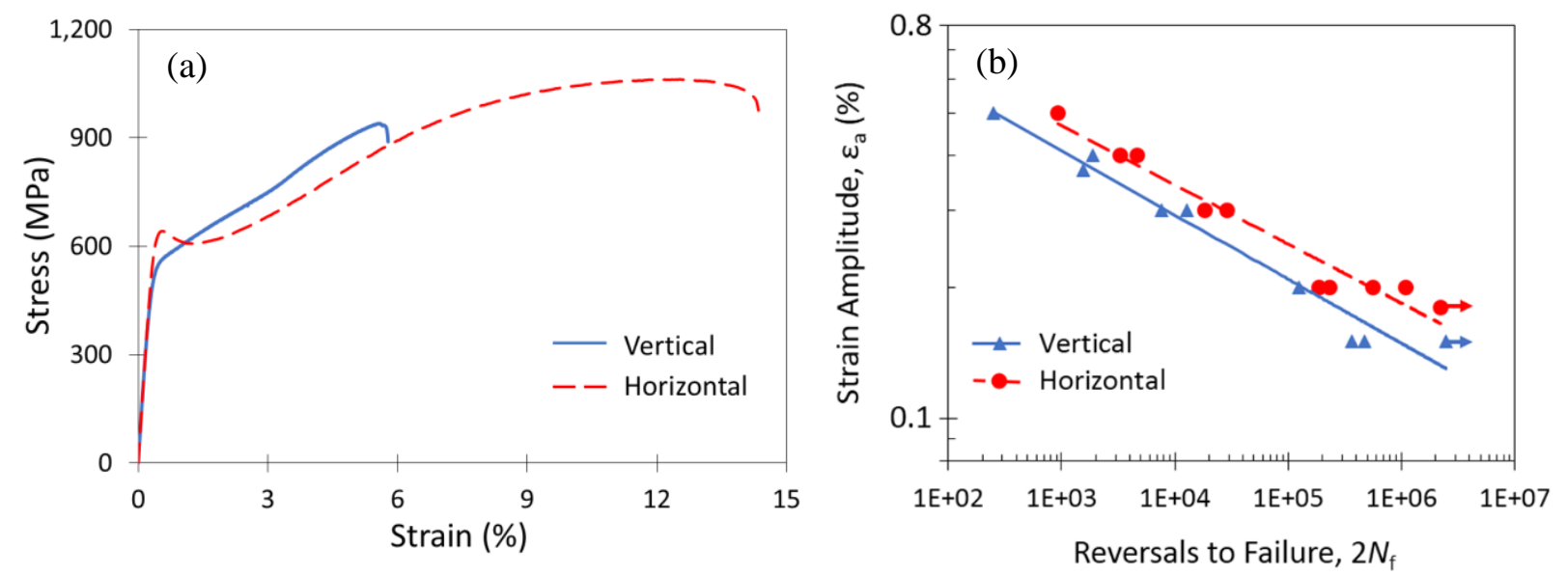

Fig. 5. (a) Engineering stress-strain curves, and (b) fully-reversed $\left(R_{\varepsilon}=-1\right)$ strain-life fatigue experimental data for vertically- and horizontally-built L-PBF 17-4 PH SS in as-built condition [11]. 
(a) Crack growth parallel to the building orientation

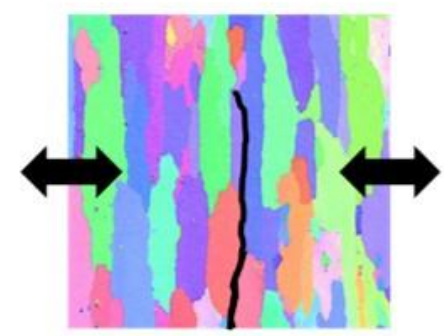

(b) Crack growth perpendicular to the building orientation

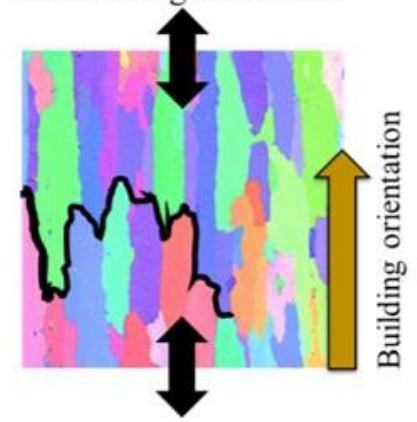

Fig. 6. Schematics demonstrating crack growth (a) parallel and (b) perpendicular to the elongated grains along the building direction (double arrows show the applied loading direction). 

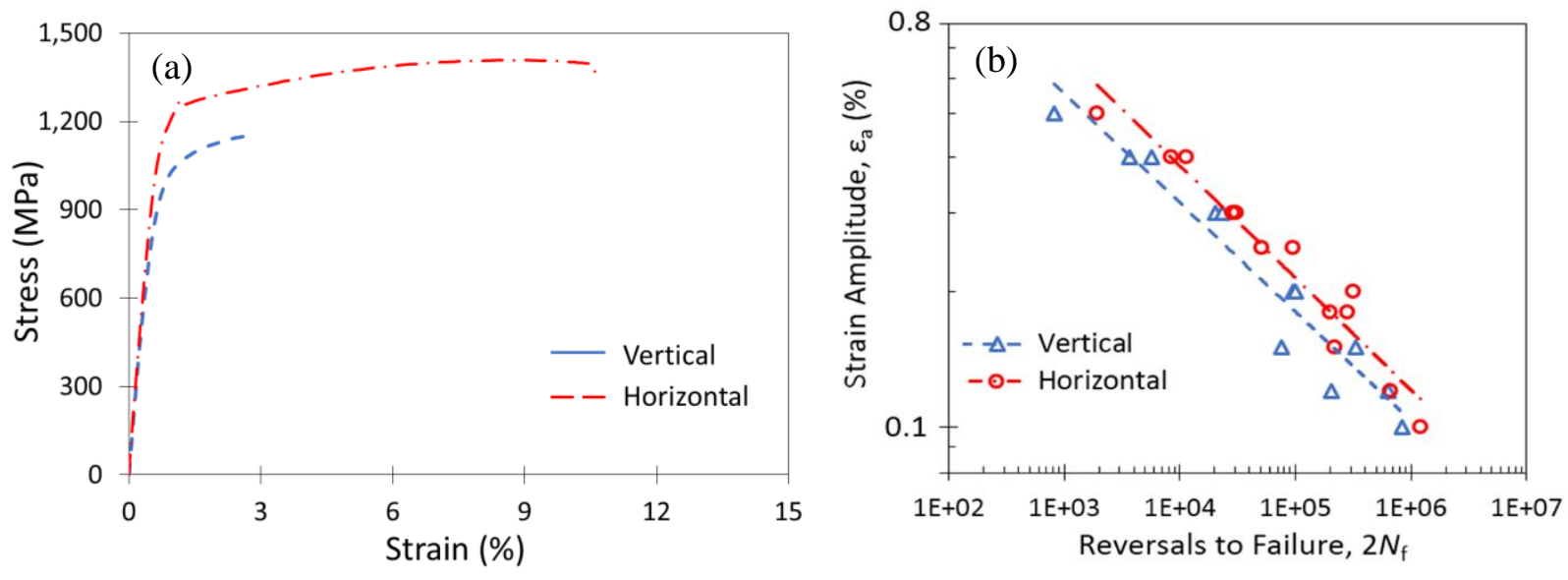

Fig. 7. (a) Engineering stress-strain curves and (b) fully-reversed $\left(R_{\varepsilon}=-1\right)$ strain-life fatigue experimental data for L-PBF 17-4 PH SS, vertically- and horizontally-built, in heat treated condition [11]. 
(a)

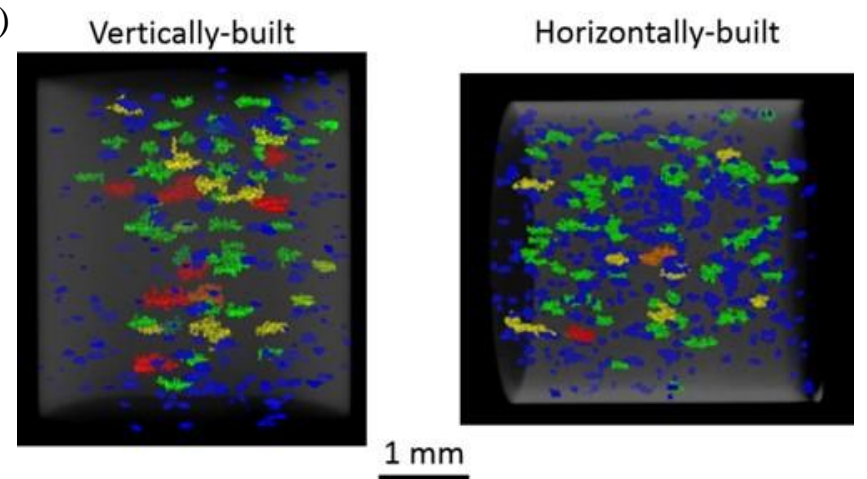

(b)

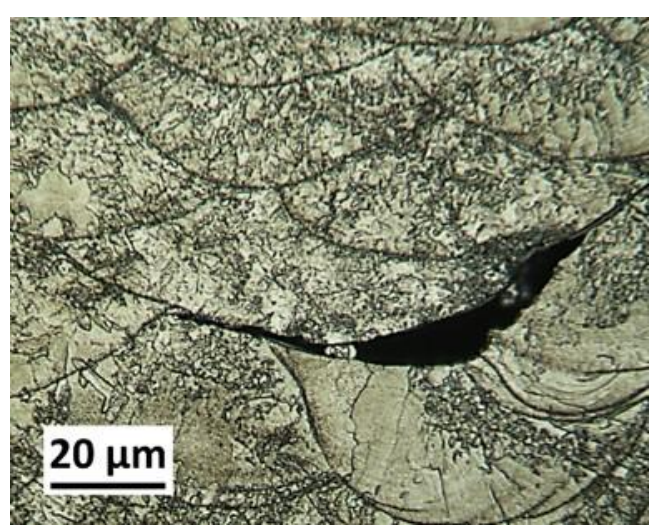

(c)

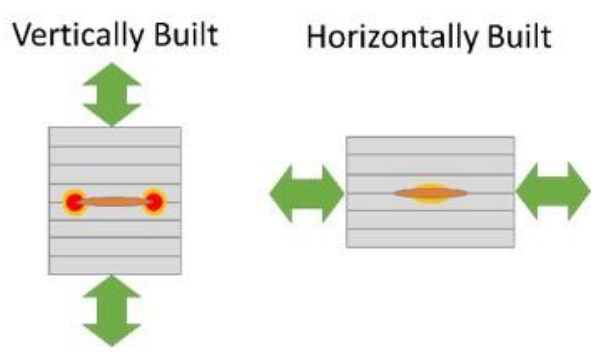

Fig. 8. (a) 3D volumetric image of X-ray CT scan for vertical and horizontal L-PBF 17-4 PH SS specimens showing the void distribution within the gage section (different colors represent different void sizes), (b) radial cross-section images of a horizontal L-PBF 17-4 PH SS specimen in as-built condition, and (c) schematics representing the orientation of a void formed between layers of vertical and horizontal specimens with respect to the loading direction and the resultant stress concentrations [11]. 

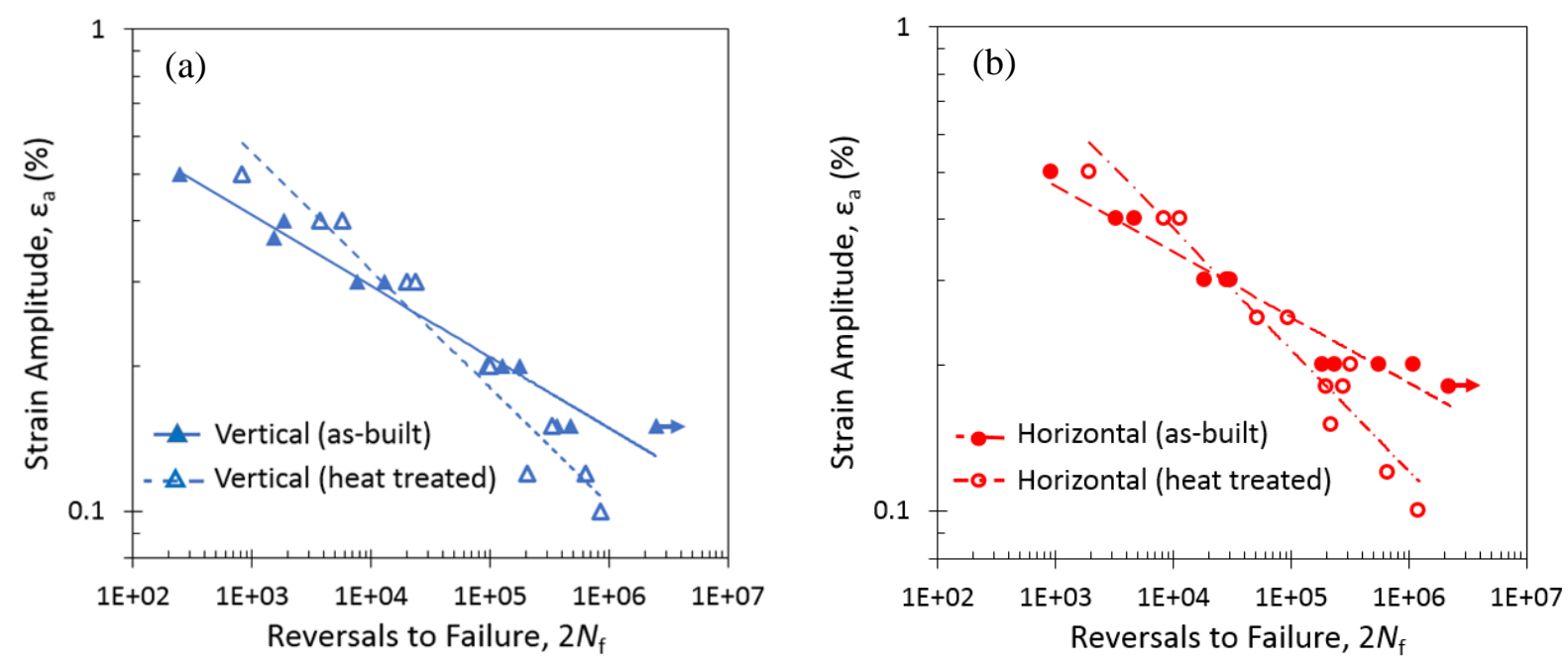

Fig. 9. Fully-reversed $\left(R_{\varepsilon}=-1\right)$ strain-life fatigue experimental data and fits for (a) vertical, and (b) horizontal L-PBF 17-4 PH SS in as-built and heat treated conditions [11]. 


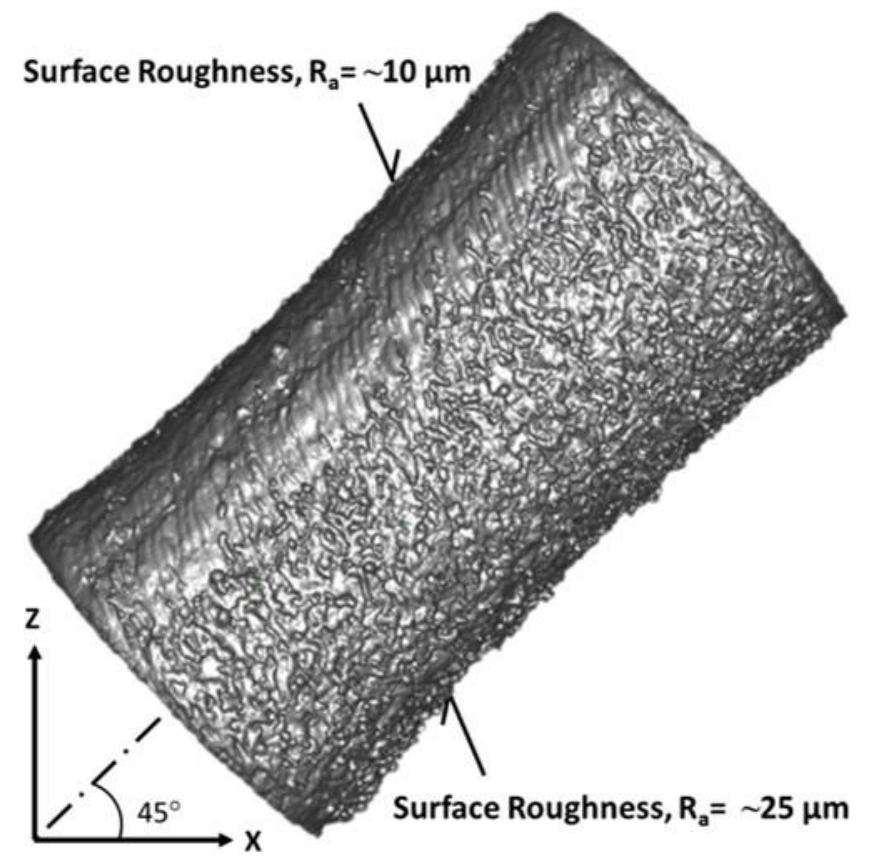

Fig. 10. X-ray CT image of a $45^{\circ}$ orientated Inconel 718 specimen, fabricated via an L-PBF method, showing a higher surface roughness for the overhanging side (i.e. downward facing side toward the build-plate) relative to the contracting surface (i.e. upward facing side) [19]. 


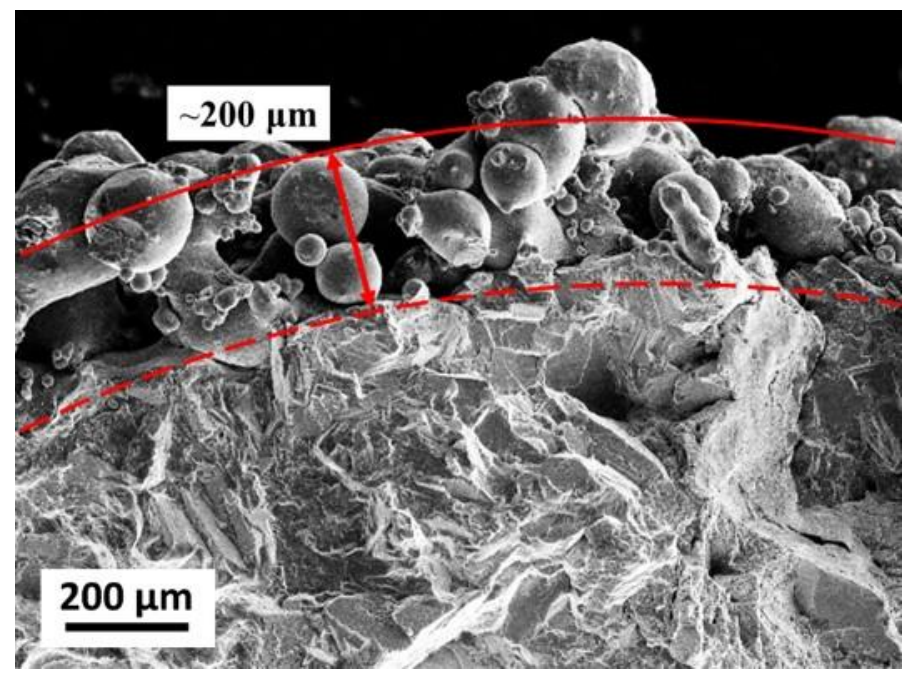

Fig. 11. Presence of partially-melted powders on gage section of as-built specimens, causing errors during measurement of fatigue specimens' diameter. The specimen's diameter is approximately $5 \mathrm{~mm}$. 


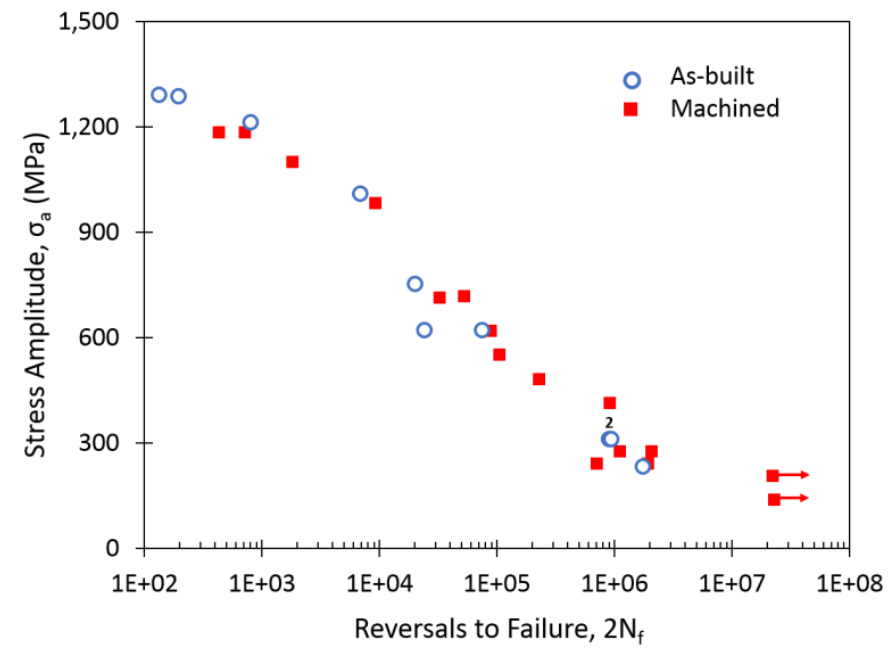

Fig. 12. Room temperature fully-reversed $\left(R_{\sigma}=-1\right)$ uniaxial fatigue stress-life data for L-PBF Inconel 718 in machined and as-built conditions [19]. 
(a)

(b)
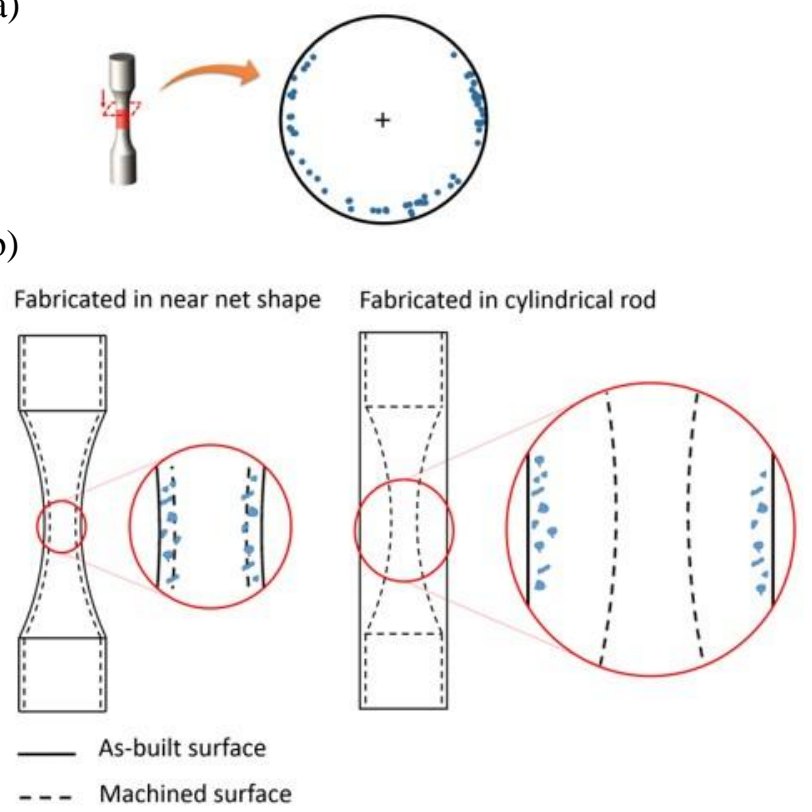

Fig. 13. (a) Distribution of voids mapped on the cross sectional view of a gage section, captured by X-ray CT scan of an as-built specimen [19], and (b) schematics showing different specimen designs, including fabricating the near net shape specimen or cylindrical rod. 


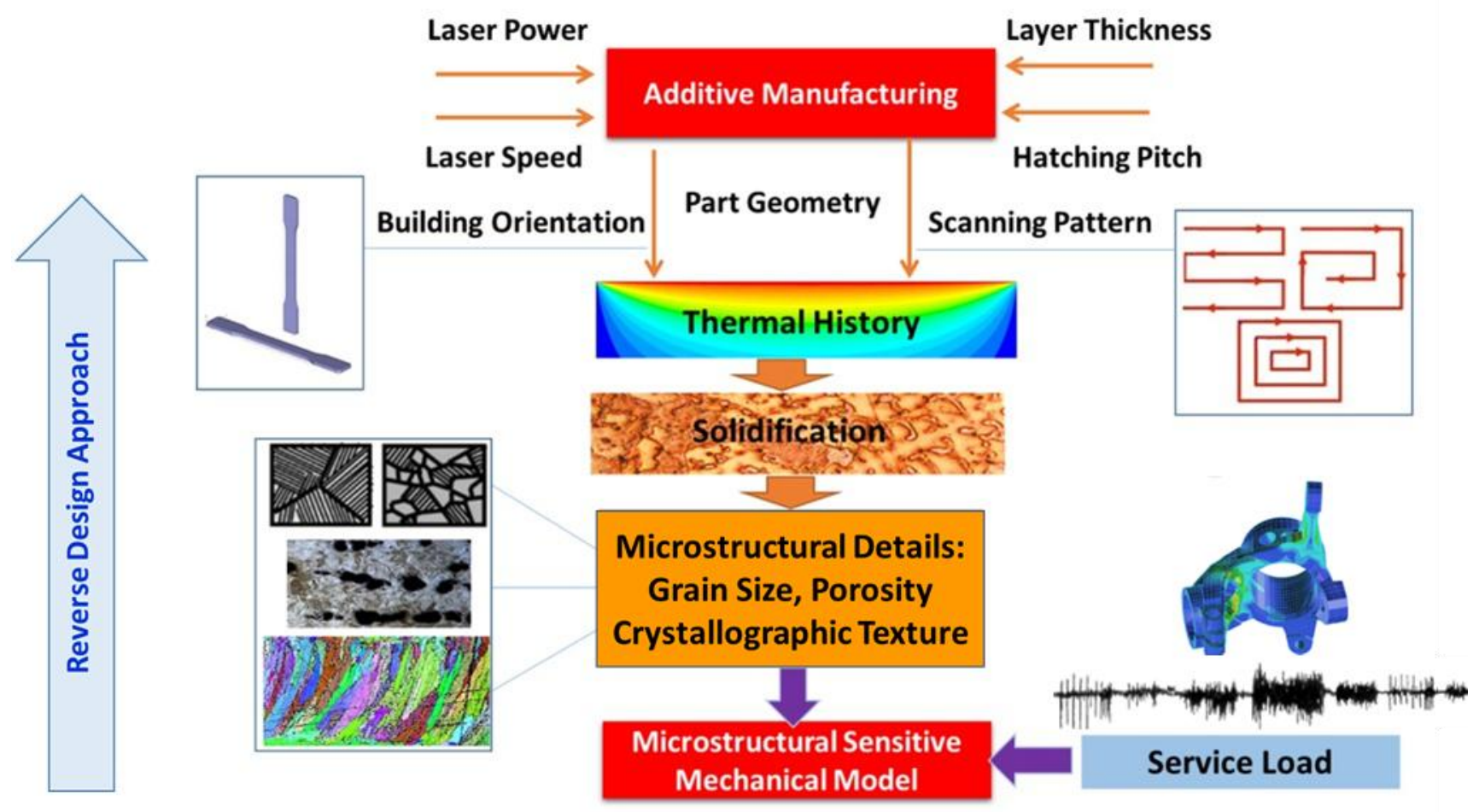

Fig. 14. Relationships among manufacturing process parameters, thermal history, solidification, microstructure, and mechanical behavior of AM parts [9]. 


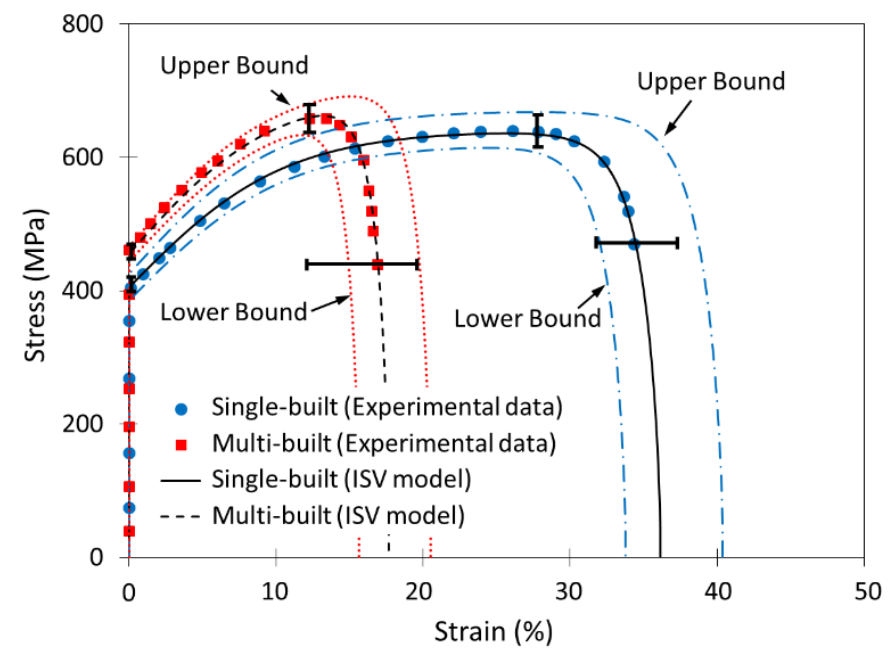

Fig. 15. ISV plasticity-damage model predictions of lower and upper bounds as compared with the experimental data and scatter bands (shown by error bars) for single-built and multi-built DLD 316L SS [75]. 


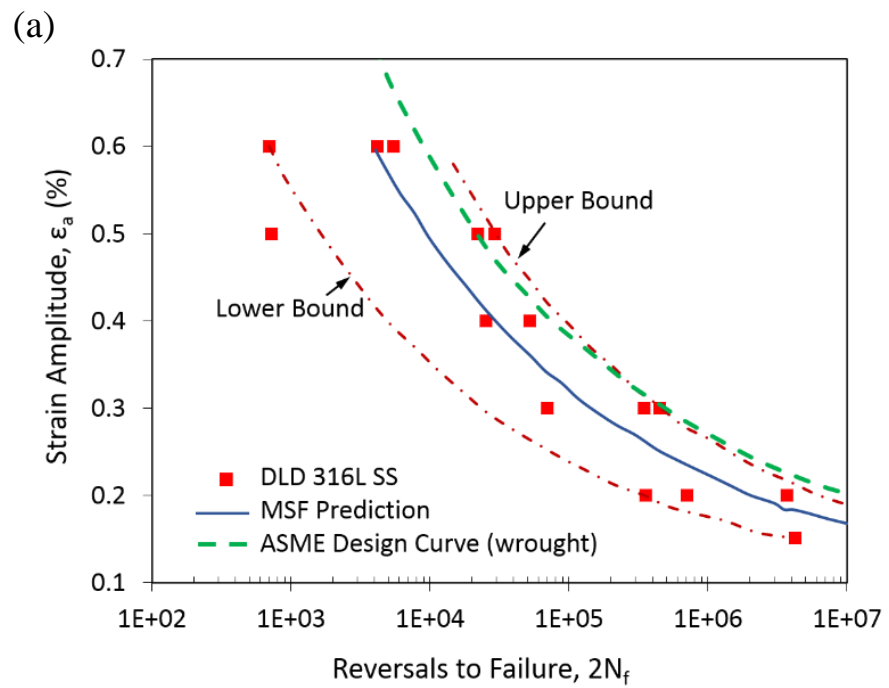

(b)

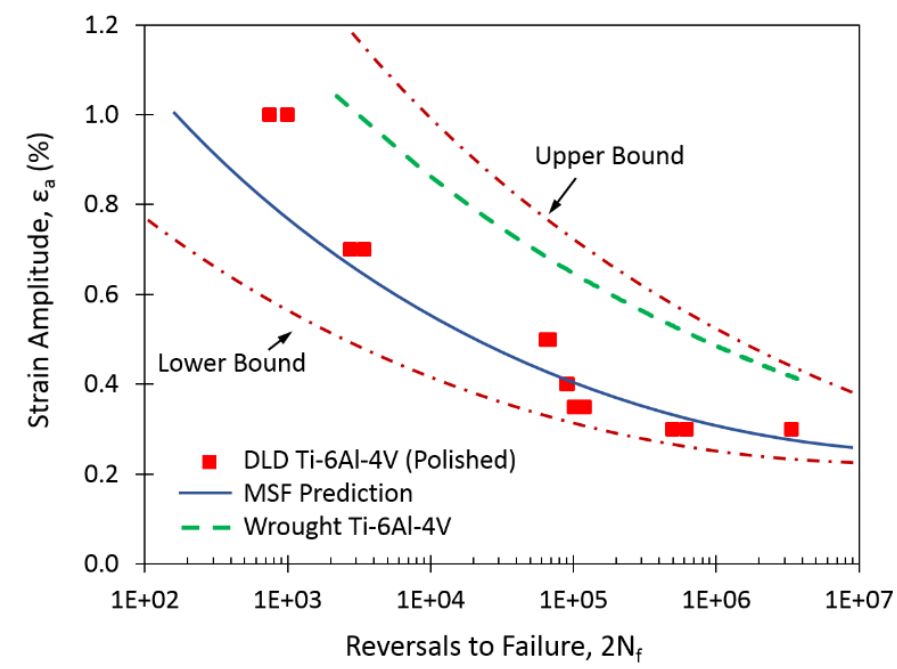

Fig. 16. Fatigue life predictions using a microstructural sensitive fatigue model for (a) DLD 316L SS [77], and (b) DLD Ti-6Al-4V [78] data. Experimental strain life fatigue curves for conventionally-built materials $[23,82]$ are also superimposed. 


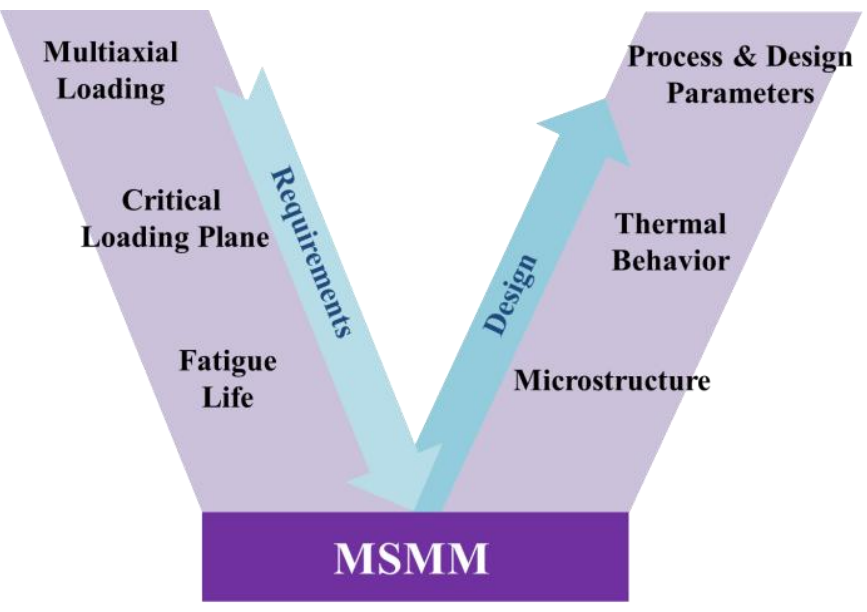

Fig. 17. The approach introduced to design fabricated AM parts with enhanced structural integrity under general service loading. MSMM stands for microstructural sensitive mechanical models. 

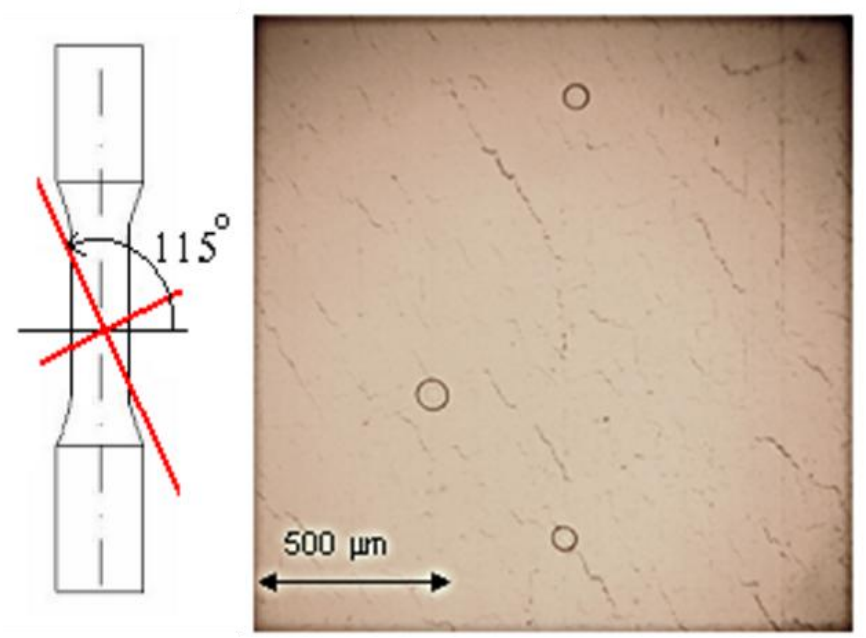

Fig. 18. Preferred cracking orientation observed for 1050 normalized steel under in-phase (IP) axial-torsion loading [60]. 

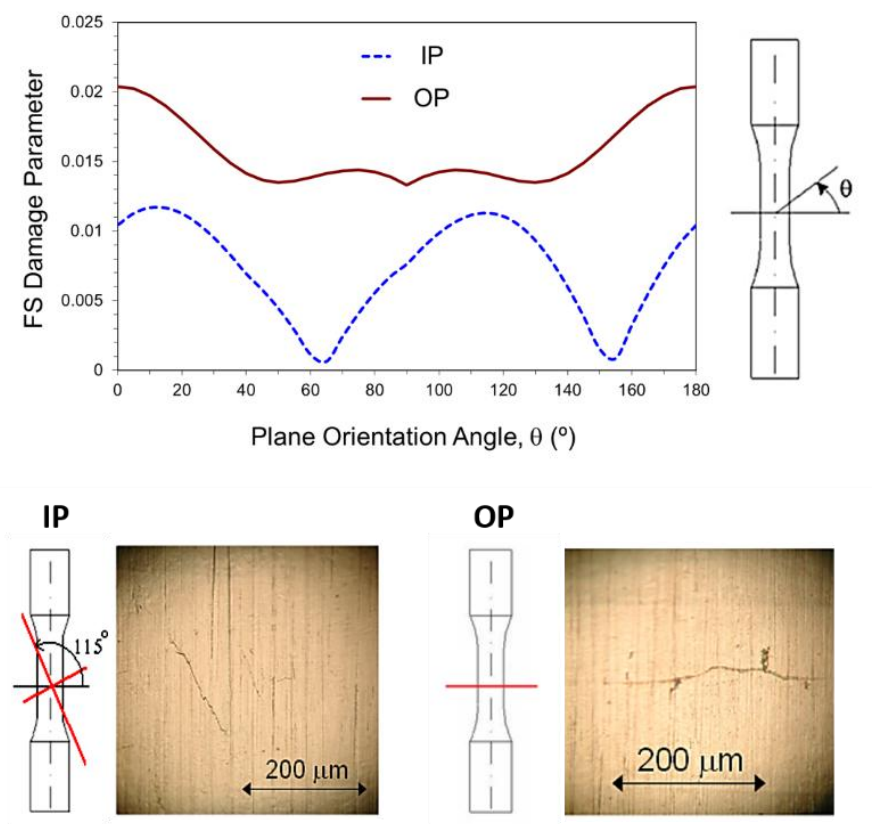

Fig. 19. Variation of FS damage parameter with plane orientation under in-phase (IP) and $90^{\circ}$ out-of-phase (OP) axial-torsion loadings at the same strain levels [80]. The observed cracking orientations are also demonstrated. 